OPEN ACCESS

Edited by:

Qunxin She,

Shandong University, China

Reviewed by:

Gabriella Fiorentino,

University of Naples Federico II, Italy

Xu Peng,

University of Copenhagen, Denmark

*Correspondence:

Eveline Peeters

Eveline.Peeters@vub.be

Specialty section:

This article was submitted to

Biology of Archaea,

a section of the journal

Frontiers in Microbiology

Received: 19 June 2019

Accepted: 23 August 2019

Published: 10 September 2019

Citation:

Lemmens L, Tilleman $L$,

De Koning E, Valegård K, Lindås A-C,

Van Nieuwerburgh F, Maes $D$ and

Peeters E (2019) YtrA $A_{\text {Sa, }}$

a GntR-Family Transcription Factor,

Represses Two Genetic Loci

Encoding Membrane Proteins

in Sulfolobus acidocaldarius.

Front. Microbiol. 10:2084.

doi: 10.3389/fmicb.2019.02084

\section{YtrAsa, a GntR-Family Transcription Factor, Represses Two Genetic Loci Encoding Membrane Proteins in Sulfolobus acidocaldarius}

\author{
Liesbeth Lemmens ${ }^{1}$, Laurentijn Tilleman ${ }^{2}$, Ezra De Koning ${ }^{1}$, Karin Valegård ${ }^{3}$, \\ Ann-Christin Lindås ${ }^{4}$, Filip Van Nieuwerburgh ${ }^{2}$, Dominique Maes $^{5}$ and Eveline Peeters ${ }^{1 *}$ \\ 1 Research Group of Microbiology, Department of Bioengineering Sciences, Vrije Universiteit Brussel, Brussels, Belgium, \\ ${ }^{2}$ Laboratory for Pharmaceutical Biotechnology, Faculty of Pharmaceutical Sciences, Ghent University, Ghent, Belgium, \\ ${ }^{3}$ Molecular Biophysics, Department of Cell and Molecular Biology, Uppsala University, Uppsala, Sweden, ${ }^{4}$ Department \\ of Molecular Biosciences, The Wenner-Gren Institute, Stockholm University, Stockholm, Sweden, ${ }^{5}$ Structural Biology \\ Brussels, Department of Bioengineering Sciences, Vrije Universiteit Brussel, Brussels, Belgium
}

In bacteria, the GntR family is a widespread family of transcription factors responsible for the regulation of a myriad of biological processes. In contrast, despite their occurrence in archaea only a little information is available on the function of GntRlike transcription factors in this domain of life. The thermoacidophilic crenarchaeon Sulfolobus acidocaldarius harbors a GntR-like regulator belonging to the YtrA subfamily, encoded as the first gene in an operon with a second gene encoding a putative membrane protein. Here, we present a detailed characterization of this regulator, named YtrA $_{S a}$, with a focus on regulon determination and mechanistic analysis with regards to DNA binding. Genome-wide chromatin immunoprecipitation and transcriptome experiments, the latter employing a $y t r A_{S a}$ overexpression strain, demonstrate that the regulator acts as a repressor on a very restricted regulon, consisting of only two targets including the operon encoding its own gene and a distinct genetic locus encoding another putative membrane protein. For both targets, a conserved 14-bp semi-palindromic binding motif was delineated that covers the transcriptional start site and that is surrounded by additional half-site motifs. The crystallographic structure of YtrA $\mathrm{Sa}_{\mathrm{Sa}}$ was determined, revealing a compact dimeric structure in which the DNAbinding motifs are oriented ideally to enable a specific high-affinity interaction with the core binding motif. This study provides new insights into the functioning of a YtrA-like regulator in the archaeal domain of life.

Keywords: archaea, Sulfolobus, transcription regulation, GntR, YtrA, membrane protein

\section{INTRODUCTION}

The GntR family of transcription factors (TFs), named after a gluconate operon repressor first characterized in Bacillus subtilis (Fujita et al., 1986), is a widespread and abundant TF family amongst prokaryotes (Haydon and Guest, 1991; Rigali et al., 2002; Hoskisson and Rigali, 2009; Suvorova et al., 2015). In bacteria, it is the fourth largest TF family representing about $8 \%$ of all regulators (Pérez-Rueda et al., 2018). Members of the GntR superfamily regulate a variety of biological processes, for example metabolic pathways, morphogenesis, sporulation, cell envelope 
stress response or the production of secondary metabolites such as antibiotics (Rigali et al., 2002; Hillerich and Westpheling, 2006; Hoskisson and Rigali, 2009; Ostash et al., 2011; Salzberg et al., 2011). GntR-type TFs harbor a DNA-binding domain at their $\mathrm{N}$-terminus with a typical helix-turn-helix (HTH) motif that is characterized by a highly conserved secondary structure, despite an overall low sequence identity (Rigali et al., 2002). In addition to the structurally conserved N-terminal domain, a divergent effector-binding/oligomerization domain (E-O domain) can be discerned at the C-terminus. Effector binding typically induces conformational changes in the dimeric protein, thereby affecting binding to a palindromic binding motif (Rigali et al., 2002; Gao et al., 2007). The E-O domain shows a large variability in terms of length, structure and oligomerization mechanism. Based on this heterogeneity in the E-O domain, GntR-type TFs are further classified in at least six subfamilies: FadR, MocR, HutC, YtrA, AraA, and PlmA (Rigali et al., 2002; Suvorova et al., 2015).

YtrA is a GntR subfamily that is prototyped by the YtrA TF of Bacillus subtilis, which regulates acetoin utilization and is responsive to cell wall antibiotics suggesting that is involved in cell envelope stress response (Yoshida et al., 2000; Salzberg et al., 2011). Although the YtrA subfamily is the least represented of all GntR subfamilies in bacterial genomes (Vindal et al., 2007), an evolutionary expansion has been observed in certain bacterial phyla, such as Grampositive Firmicutes and Actinobacteria (Suvorova et al., 2015), with the latter having multiple YtrA homologs in a single genome (Tsypik et al., 2016). The actinomycete Streptomyces coelicolor harbors several YtrA-like TFs with likely at least partially overlapping functions, for example in controlling genes affecting morphogenesis and antibiotic production (Hillerich and Westpheling, 2006; Tsypik et al., 2016). YtrA-like TFs are generally encoded as the first gene in an operon also encoding an ATP-binding cassette (ABC) transport system (Rigali et al., 2002; Hoskisson and Rigali, 2009). By repressing transcription of this operon, YtrA regulators simultaneously target their own transcription and that of the co-encoded $\mathrm{ABC}$ transport system. A phylogenomic study in actinomycetes revealed that in this bacterial clade, in which YtrA-like TFs are abundant, exceptions exist with respect to the genomic colocalization of YtrA-encoding genes and genes coding for ABC transport systems (Tsypik et al., 2016). More specifically, one group of YtrA-like TFs was characterized by an operonic colocalization with genes predicted to encode membrane proteins (Tsypik et al., 2016). The function of these membrane proteins and the role of their regulation by a YtrA regulator remains unclear (Tsypik et al., 2016).

YtrA members, with a total average length of 120 to 130 amino acids, are typified by a relative small E-O domain, with approximately 50 amino acids folding into two $\alpha$-helices (Rigali et al., 2002). Structural analysis of a YtrA-like TF of Corynebacterium glutamicum demonstrated that these $\alpha$-helices mediate dimerization of the protein (Gao et al., 2007). Despite the small size of the E-O domain, the dimerization mode resulted in an extended global structure, with the two monomeric HTH motifs being separated by a relatively large distance (Gao et al., 2007). Such a structure is in line with the observation that the palindromic binding motif is longer for members of the YtrA subfamily with respect to other subfamilies (Rigali et al., 2002; Vindal et al., 2007). Indeed, the YtrA binding motif is typically 24 base pairs (bp) long and characterized by distantly located half sites harboring conserved palindromic residues that are contacted by the respective HTH motifs (Rigali et al., 2002; Gao et al., 2007). Given the small E-O domain it was hypothesized that YtrAlike regulators might not be capable of forming a ligandbinding pocket (Yoshida et al., 2000; Rigali et al., 2002). Although this hypothesis was refuted by the observation of 2-methyl-2,4-pentanediol (MPD) molecules interacting in the E-O domain of the crystallized C. glutamicum YtrA-like protein (Gao et al., 2007), MPD does not allosterically affect this regulator and, moreover, a biologically relevant ligand has not yet been identified for a YtrA member (Gao et al., 2007; Salzberg et al., 2011).

Archaea harbor, despite being characterized by a eukaryoticlike transcription machinery (Bell and Jackson, 2001), TFs belonging to typical bacterial TF families (Pérez-Rueda and Janga, 2010). Phylogenomic predictions indicate that TFs of the GntR family can also be recognized in archaeal genomes, although they represent only $1.3 \%$ of the total predicted TF repertoire and are thus significantly less abundant as compared to bacteria (Pérez-Rueda et al., 2018). Despite representing only a minor proportion of archaeal TFs, several GntR-like regulators are predicted in both Eury- and Crenarchaeota (Pérez-Rueda et al., 2018). To our knowledge, no archaeal GntR-like transcriptional regulator has been experimentally described. It is unclear whether the physiological functions and molecular mechanisms in archaea are reminiscent of the bacterial GntR members. The thermoacidophilic model crenarchaeote Sulfolobus acidocaldarius is predicted to harbor a gene encoding a putative GntR-type TF belonging to the YtrA subfamily. Here, we aim at characterizing this TF, named YtrA $\mathrm{Sa}_{\mathrm{Sa}}$, by unraveling its structure, DNA-binding characteristics and regulon.

\section{MATERIALS AND METHODS}

\section{Bioinformatic Analysis}

Homology searches were performed using Standard Protein BLAST (National Center for Biotechnology Information) and SyntTax (Oberto, 2013). Multiple sequence alignments were constructed with MUSCLE (Edgar, 2004). Archaeal genomes were explored using the UCSC Archaeal Genome Browser (Chan et al., 2012). The RSAT suite was used for the prediction of binding motifs (Nguyen et al., 2018). Sequence logos were prepared with WebLogo (Crooks et al., 2004).

\section{Microbial Strains and Growth Conditions}

Sulfolobus acidocaldarius strains were cultivated in basic Brock medium (Brock et al., 1972) supplemented with (w/v) 0.2\% sucrose and (w/v) $0.1 \% \mathrm{~N}$-Z-amine. The $\mathrm{pH}$ of the medium was adjusted to 3.5 using sulfuric acid. Microbial growth was performed at $75^{\circ} \mathrm{C}$ in a shaking incubator and was followed 
by measurement of optical density at $600 \mathrm{~nm}\left(\mathrm{OD}_{600}\right)$. For cultivation of the uracil auxotrophic strains MW001 (Wagner et al., 2012) and SK-1 (Suzuki and Kurosawa, 2016), the growth medium was supplemented with $10 \mathrm{mg} / \mathrm{ml}$ uracil. To induce expression under the control of Pmal, $0.4 \%$ maltose was added to the growth medium. For growth on solid medium, Brock medium was solidified by the addition of $0.6(\mathrm{w} / \mathrm{v}) \%$ gelrite, $10 \mathrm{mM} \mathrm{MgCl}_{2}$ and $3 \mathrm{mM} \mathrm{CaCl}_{2}$.

Escherichia coli strains were used for propagation of plasmid DNA constructs and heterologous protein overexpression and were grown while shaking at $37^{\circ} \mathrm{C}$ in Lysogeny Broth (LB) medium supplemented with $50 \mu \mathrm{g} / \mathrm{ml}$ ampicillin, $50 \mu \mathrm{g} / \mathrm{ml}$ kanamycin, and/or $34 \mu \mathrm{g} / \mathrm{ml}$ chloramphenicol, depending on the used strain and plasmid construct. An overview of all strains used in this work is given in Supplementary Table S1.

\section{Nucleic Acid Manipulations and Molecular Cloning}

For genomic DNA (gDNA) extractions, S. acidocaldarius cells were cultivated to an $\mathrm{OD}_{600}$ of 0.8 , followed by centrifugation at $7000 \mathrm{rpm}$ and a magnetic-bead based purification using a QuickPick ${ }^{\mathrm{TM}}$ SML gDNA kit (Bio-Nobile) according to manufacturer's instructions. For RNA extractions, cultures were grown until reaching an $\mathrm{OD}_{600}$ of 0.4 , after which 4 -ml samples were treated with RNAprotect Bacteria Reagent (Qiagen) and pelleted. Total RNA was purified using an RNeasy Mini Kit (Qiagen) with an additional on-column DNase I treatment using the RNase-free DNase set (Qiagen). RNA samples were tested for integrity using RNA gel electrophoresis and stored at $-80^{\circ} \mathrm{C}$ until further analysis.

Using S. acidocaldarius gDNA, the $\mathrm{YtrA}_{\mathrm{Sa}}$-encoding gene, Saci_1851, was amplified with oligonucleotides LL106 and LL107 and cloned into a pET24a expression vector by traditional restriction-ligation cloning using the $\mathrm{NdeI}$ and XhoI restriction sites. An overview of all oligonucleotide sequences and plasmid constructs used in this work is presented in Supplementary Tables S2, S3, respectively. Cloning was performed in E. coli using heat-shock transformations.

A Sulfolobus/E. coli shuttle vector plasmid enabling to overexpress $y \operatorname{tr} A_{S a}$ in $S$. acidocaldarius was generated in multiple steps in E. coli, starting from the pRN1-derived pSVA1450 (Wagner et al., 2012). In a first step, vector pJL1602 was constructed by replacing the maltose-inducible promoter Pmal upstream of lacS by a synthetic expression region harboring a multiple cloning site (MCS) (consisting of 5 unique restriction sites NdeI, NotI, SalI, PstI, and NheI) flanked by two constitutive promoters (natural promoters of Sso0389 and Sso1927, respectively). To this end, a ligase chain reaction approach was performed for oligonucleotides EP479-EP494 (Supplementary Table S2) followed by cloning using the Seamless Ligation Cloning Extract (SLiCE) technique (Zhang et al., 2012). Linearization of the plasmid was performed by SacII and NcoI restriction, while the insert fragment was prepared by amplifying the synthetic expression region using primers EP495 and EP496 (Supplementary Table S2). Next, the Sso0389 promoter was replaced by Pmal with a traditional cloning approach using SacII and SalI restriction sites, thereby generating pLL1601. Finally, the Saci_1851 gene was PCRamplified from S. acidocaldarius gDNA and cloned into the MCS downstream of Pmal using SdaI and BspOI restriction sites, thus generating pLL1601 $x y \operatorname{tr} A_{S a}$.

The YtrA $A_{S a}$-overexpression construct pLL1601xytrA $A_{S a}$ was transformed into $S$. acidocaldarius SK-1 as described (Suzuki and Kurosawa, 2016), using a Gene Pulser II electroporator (Bio-Rad) with parameter setting $1.5 \mathrm{kV}, 25 \mu \mathrm{F}$ and $600 \Omega$ and with $1-\mathrm{mm}$ cuvettes (Bio-Rad). Overexpression of $y \operatorname{tr} A_{S a}$ was confirmed in the presence of maltose using a quantitative reverse transcriptase PCR (RT-qPCR) approach as described below with primers LL021 and LL022 (Supplementary Table 2 and Supplementary Figure S1). Growth was not affected by $y \operatorname{tr} A_{S a}$ overexpression.

\section{Heterologous Ytrsa Expression and Protein Purification}

After transforming E. coli Rosetta (DE3) with pET24axytrAsa, the strain was cultivated in liquid medium until reaching an $\mathrm{OD}_{600}$ of 0.6 , followed by induction with $1 \mathrm{mM}$ isopropyl$\beta$-D-1-thiogalactopyranoside (IPTG) and further cultivation during about $16 \mathrm{~h}$. Subsequently, cells were harvested by centrifugation, resuspended in lysis buffer $(50 \mathrm{mM}$ $\mathrm{Na}_{2} \mathrm{HPO}_{4}, 0.3 \mathrm{M} \mathrm{NaCl}, \mathrm{pH}$ 8.0) and lysed by sonication. Lysed cells were centrifuged and the soluble phase containing heterologously expressed YtrA $\mathrm{A}_{\mathrm{Sa}}$ protein was collected. Next, this C-terminally His-tagged recombinant protein was purified by affinity chromatography using an ÄKTA-fast protein liquid chromatography (FPLC) system with a 5-ml HisTrap FF column (GE Healthcare). Fractional elution was accomplished by setting a linear gradient between buffer $\mathrm{A}$ (20 mM Na $2 \mathrm{HPO}_{4}, 0.5 \mathrm{NaCl}, 40 \mathrm{mM}$ imidazole, $\mathrm{pH} \mathrm{7.4)} \mathrm{and}$ buffer $\mathrm{B}\left(20 \mathrm{mM} \mathrm{Na} \mathrm{HPO}_{4}, 0.5 \mathrm{NaCl}, 500 \mathrm{mM}\right.$ imidazole, $\mathrm{pH}$ 7.4). YtrA $\mathrm{A}_{\mathrm{Sa}}$-containing fractions were analyzed by sodium dodecyl sulfate-polyacrylamide gel electrophoresis (SDS-PAGE), followed by dialysis into a storage buffer (50 $\mathrm{mM} \mathrm{Na}_{2} \mathrm{HPO}_{4}$, $150 \mathrm{mM} \mathrm{NaCl}, \mathrm{pH} 7.4$ ).

For the preparation of selenomethionine (SeMet)-substituted YtrAsa protein, a metabolic inhibition protocol was performed (Lejon et al., 2008). To this end, 2.5-ml culture of E. coli B834 (DE3/pLysS) cells transformed with pET24axytrA $A_{S a}$ was grown during $3 \mathrm{~h}$ in LB medium supplemented with kanamycin and used to inoculate $45 \mathrm{ml} \mathrm{M} 9$ minimal medium $(50 \mathrm{mM}$ $\mathrm{Na}_{2} \mathrm{HPO}_{4}, 3 \mathrm{~g} / \mathrm{l} \mathrm{KH}_{2} \mathrm{PO}_{4}, 0.5 \mathrm{~g} / \mathrm{l} \mathrm{NaCl}, 1 \mathrm{~g} / \mathrm{l} \mathrm{NH} \mathrm{NH}_{4} \mathrm{Cl}$ ) and $5 \mathrm{ml} \mathrm{LB}$ medium, also supplemented with kanamycin. The growth was continued until an $\mathrm{OD}_{600}$ of 0.7 was reached. After that, $50 \mathrm{ml}$ of the culture was added to $900 \mathrm{ml}$ M9 medium and $100 \mathrm{ml} \mathrm{LB}$ medium supplemented with $2 \mathrm{mM} \mathrm{MgSO}_{4}, 0.1 \mathrm{mM} \mathrm{CaCl} 2,0.4 \%$ glucose and $25 \mathrm{mg} / \mathrm{ml}$ kanamycin, which was further cultivated until an $\mathrm{OD}_{600}$ between 0.4 and 0.6 was reached. Next, following L-amino acids were added: Lys, Phe and Tyr (100 mg/l), Leu, Ile and Thr (50 mg/l) and L-SeMet (Acros Organics; final concentration of $60 \mathrm{ml} / \mathrm{l})$. After $10 \mathrm{~min}$, protein expression was induced by adding $0.4 \mathrm{mM}$ IPTG followed by overnight 
incubation. The SeMet-substituted protein was purified by employing the same procedure as described above. All YtrA $\mathrm{A}_{\mathrm{Sa}}$ protein preparations were pure, as judged by SDS-PAGE (Supplementary Figure S2A).

\section{Chromatin Immunoprecipitation}

Chromatin immunoprecipitation (ChIP) was performed as previously described (Liu et al., 2016). Triplicates of 20-ml S. acidocaldarius SK-1 cultures were incubated until reaching an $\mathrm{OD}_{600}$ of about 0.4 . Crosslinking was achieved by the addition of formaldehyde at a final concentration of $1 \%$, immediately after the culture was taken out the incubator, followed by an incubation at room temperature while shaking during $5 \mathrm{~min}$. Next, the crosslinking reaction was quenched by adding glycine at a final concentration of $125 \mathrm{mM}$, again followed by a 5min shaking incubation at room temperature. The cultures were centrifuged at $7000 \mathrm{rpm}$ for $10 \mathrm{~min}$, washed twice in PhosphateBuffered Saline (PBS) buffer and dissolved in $1.5 \mathrm{ml}$ IP buffer [50 mM Hepes-KOH ( $\mathrm{pH}$ 7.5), 150 mM NaCl, 1 mM EDTA, $1 \%$ Triton X-100, 0.1\% sodium deoxycholate, $0.1 \%$ SDS, protease inhibitor cocktail (Roche Applied Science)]. Subsequently, cells were subjected to sonication as described (Nguyen-Duc et al., 2013a) resulting in obtaining DNA fragments with a length ranging between 100 and $800 \mathrm{bp}$. The ChIP assay itself was done with affinity-purified polyclonal anti-YtrA $A_{S a}$ rabbit antibodies raised against the purified protein (Innovagen). A procedure was performed using Dynabeads M-280 sheep anti-rabbit IgG beads (Life Technologies) (Smollett et al., 2012). As a mock control, a similar sample was prepared without the addition of the $\mathrm{Ytr}_{\mathrm{Sa}}$-specific antibody preparation. Finally, ChIP-DNA was purified using the IPure DNA extraction kit (Diagenode). The concentration of these ChIP-DNA samples, measured using the Qubit dsDNA High Sensitivity Assay Kit (Thermo Fisher Scientific), was between 0.5 and $3.12 \mathrm{ng} / \mu \mathrm{L}$.

For high-throughput sequencing analysis, $20 \mu \mathrm{l}$ of DNA was prepared using the NEBNext Ultra II DNA Library Prep Kit for Illumina (New England Biolabs) according to the manufacturer's protocol. During this library preparation, 14 PCR cycles were used for all samples. Libraries were quantified by quantitative PCR (qPCR), according to Illumina's protocol 'Sequencing Library qPCR Quantification protocol guide', version February 2011. A DNA 1000 chip (Agilent Technologies) was used to control the library's size distribution and quality. Libraries were equimolarly pooled and sequencing was performed on a highthroughput Illumina NextSeq 500 flow cell generating 75 bp single reads. Per sample, on average, $30.5 \pm 5.0$ million reads were generated. First, these reads were trimmed using cutadapt version 1.17 (Martin, 2011) to remove the Illumina adaptor sequences. The trimmed reads were mapped against the $S$. acidocaldarius DSM639 GCA_000012285.1 reference genome sequence (Chen et al., 2005) using Bowtie2 version 2.2.5 (Langmead and Salzberg, 2012). For each sample, a Tag Directory was made with HOMER version 4.10 (Heinz et al., 2010). Mock samples were used as a control for enriched samples in the findPeaks algorithm of the HOMER suite (Heinz et al., 2010). ChIP-sequencing (ChIPseq) results were visualized using Integrative Genomics Viewer version 2.4.19 (Robinson et al., 2017).
Target-specific validation of ChIP enrichment was performed with qPCR for biological triplicates. To this end, purified ChIPDNA and mock samples were amplified using a My-iQ ${ }^{\mathrm{TM}}$ Single color Real-time PCR system (Bio-Rad) and GoTaq ${ }^{\circledR}$ qPCR Master Mix (Promega) as previously described (Nguyen-Duc et al., 2013b). Primer3Plus software (Rozen and Skaletsky, 2000) was used to design oligonucleotides (Supplementary Table S2) that amplify fragments around the ChIP-seq peak summit regions and with a length between 150 and $200 \mathrm{bp}$. The efficiency of oligonucleotide pairs was tested using gDNA as a template. Relative enrichment ratios were calculated following the method described in Pfaffl (2001) using an irrelevant genomic region (in the open reading frame (ORF) of Saci_1336) as a nonbinding reference.

\section{Electrophoretic Mobility Shift and Footprinting Assays}

${ }^{32}$ P-labeled DNA fragments were obtained by PCR using GoTag ${ }^{\circledR}$ Green Master Mix (Promega) and for each fragment, a $5^{\prime}$ end-labeled oligonucleotide and a non-labeled oligonucleotide (Supplementary Table S2). As a template, S. acidocaldarius MW001 gDNA was used. Prior to this, labeled oligonucleotides were prepared using $\left[\gamma^{-32} \mathrm{P}\right]$-ATP (Perkin Elmer) and $\mathrm{T}_{4}$ polynucleotide kinase (Thermo Scientific). In case of 50-bp fragments, hybridization was performed of a ${ }^{32} \mathrm{P}$-labeled oligonucleotide with a non-labeled complementary one. All labeled DNA fragments were purified from a native polyacrylamide gel (6\%) after electrophoresis.

Electrophoretic mobility shift assays (EMSAs) were performed as described before (Enoru-Eta et al., 2000) with approximately $0.1 \mathrm{nM}{ }^{32}$ P-labeled DNA fragment, an excess of non-specific competitor DNA and varying protein concentrations. In case of ligand-binding assays, varying concentrations of aromatic compounds $(0 \mathrm{mM}, 10 \mathrm{mM}$ and $100 \mathrm{mM}$ ) were added as well. Binding reactions were prepared in Lrp binding buffer (20 mM Tris- $\mathrm{HCl}$ ( $\mathrm{pH} 8.0$ ), $1 \mathrm{mM} \mathrm{MgCl}_{2}, 0.1 \mathrm{mM}$ dithiothreitol (DTT), $12.5 \%$ glycerol, $50 \mathrm{mM} \mathrm{NaCl}, 0.4 \mathrm{mM}$ EDTA) and were incubated at $37^{\circ} \mathrm{C}$ to equilibrate prior to electrophoresis on native polyacrylamide gels (6\%). Densitometry analysis was performed by measuring the integrated density of the free DNA bands using Image J (Abramoff et al., 2004). The apparent equilibrium dissociation constant $\mathrm{K}_{\text {Dapp }}$ and Hill coefficient $\mathrm{n}$ were calculated by fitting the density data using the Hill equation as described before (Peeters et al., 2007) using GraphPad Prism software.

DNase I footprinting experiments were performed as previously described (Enoru-Eta et al., 2000; Peeters et al., 2004) with Maxam-Gilbert treated samples as sequencing ladders (Maxam and Gilbert, 1980).

\section{YtrAsa Crystallization and Structure Determination}

Crystallization of SeMet-derivated YtrA $\mathrm{A}_{S a}$ was performed at $20^{\circ} \mathrm{C}$ using the hanging-drop vapor diffusion method by mixing equal volumes of protein solution $(11 \mathrm{mg} / \mathrm{ml})$ and reservoir solution consisting of $20 \%(\mathrm{w} / \mathrm{v})$ PEG3350, $0.2 \mathrm{M}$ sodium nitrate and 
$0.1 \mathrm{M}$ Bis-Tris propane, $\mathrm{pH}$ 8.5. Needle-sized crystals were obtained after a few days (Supplementary Figure S2B). The crystals belong to space group $\mathrm{P}_{2}$, with unit-cell parameters $\mathrm{a}=\mathrm{b}=132.4 \AA, \mathrm{c}=39.2 \AA$ and $\alpha=\beta=90^{\circ}, \gamma=120^{\circ}$ and two molecules per asymmetric unit, with a Matthews coefficient of $2.5 \AA^{3} / \mathrm{Da}$ and $50.5 \%$ solvent content. Highresolution data were collected at beamlines ID23-1 and ID29 (European Synchrotron Radiation Facility (ESRF), Grenoble, France) at $-173^{\circ} \mathrm{C}$ and were processed using the XDS package (Kabsch, 2010). The structure of YtrA $\mathrm{A}_{\mathrm{Sa}}$ was determined with the ARP/Warp module of the CCP4i suite (Lamzin et al., 2012). Structure refinement was performed with PHENIX (Echols et al., 2012) and REFMAC (Murshudov et al., 2011). The C-terminal end of chain B (Asn101- Lys121) could not be built due to poor electron density. This C-terminal end also has high B-factors in chain-A. The coordinates were deposited to the Protein Data Bank.

\section{Gene Expression Analysis}

Triplicate cultures of $S$. acidocaldarius SK-1xpLL1601xytrA $A_{S a}$ and the isogenic wild type $S$. acidocaldarius SK-1xpLL1601 were grown in the presence of $0.4 \%$ maltose and subjected to RNA extraction. To initiate library preparation for an RNA sequencing (RNA-Seq) experiment, the concentration and quality of the extracted total RNA were checked using the "Quant-it Ribogreen RNA assay" (Life Technologies) and the RNA 6000 Nano Chip (Agilent Technologies), respectively. Subsequently, $2 \mu \mathrm{g}$ of RNA was used to perform a ribo depletion using the RiboZero rRNA Removal Kit (Bacteria) (Illumina) according to the manufacturer's protocol. Depleted samples were used to perform an Illumina sequencing library preparation using the TruSeq Stranded Total RNA Sample Preparation Kit (Illumina). During the library preparation, 9 PCR cycles were used. Libraries were quantified by qPCR, according to Illumina's protocol "Sequencing Library qPCR Quantification protocol guide," version February 2011. A High Sensitivity DNA chip (Agilent Technologies) was used to control the library's size distribution and quality. Libraries were equimolarly pooled and sequencing was performed on a high throughput Illumina NextSeq 500 flow cell generating 75 bp single reads. Per sample, on average, $58 \pm 31$ million reads were generated. First, these reads were trimmed using cutadapt version 1.17 (Martin, 2011) to remove the Illumina adaptor sequences. Next, the trimmed reads were mapped against the S. acidocaldarius DSM639 GCA_000012285.1 reference genome sequence (Chen et al., 2005) using STAR version 2.5.3a (Dobin et al., 2013). RSEM software version 1.2.31 (Li and Dewey, 2011), was used to generate the count tables. Differential gene expression analysis between the wild type and $y \operatorname{tr} A_{S a}$ overexpression strain was performed using edgeR (Robinson et al., 2010). First, read counts were normalized using edgeR's standard normalization method. Only genes with a counts per million (cpm) value above 1 in at least three samples were retained. A general linear model was built, and statistical testing was done using the empirical Bayes quasi-likelihood F-test. Genes characterized by a false discovery rate $($ FDR $)<0.01$ and a fold change $(\mathrm{FC})>2$ were considered as significantly differentially expressed.
For RT-qPCR analysis, first-strand cDNA was prepared from $1 \mu \mathrm{g}$ of each purified RNA sample by GoScript ${ }^{\mathrm{TM}}$ Reverse Transcriptase (Promega). Oligonucleotides were designed using Primer3Plus software (Rozen and Skaletsky, 2000) (Supplementary Table S2) and tested for efficiency using gDNA as a template. RT-qPCR was performed for biological triplicates using a Bio-Rad iCycler and GoTaq ${ }^{\circledR}$ qPCR Master Mix (Promega) as previously described (Nguyen-Duc et al., 2013b). Relative expression ratios were calculated with respect to the expression levels of the reference gene Saci_1336 (encoding TATA-binding protein) (Pfaffl, 2001).

\section{RESULTS}

\section{Identification of a YtrA Homolog in S. acidocaldarius}

Based on annotations, it is predicted that the S. acidocaldarius genome encodes a putative transcription factor belonging to the GntR family. This protein is only conserved in the closely related Sulfolobales species Acidianus manzaensis, Sulfolobus solfataricus, and Sulfolobus islandicus (Figure 1A). Closer inspection of the amino acid sequence encoded by the concerned gene (Saci_1851) learned that the C-terminal E-O domain of this 121-amino acid protein consists of about 50 amino acids predicted to fold into two $\alpha$-helices (Figure 1B), thus classifying it as a member of the YtrA subfamily (Rigali et al., 2002). We, therefore, named this putative transcription factor $\operatorname{YtrA}_{S a}$. The $y \operatorname{tr} A_{S a}$ gene is encoded as the first gene of an operon, a typical feature for YtrA-like TFs. Furthermore, this operon harbors as a second gene a membrane protein-encoding gene (Saci_1850), which is conserved as well in the four Sulfolobales species (Figure 1A). In addition, the $y \operatorname{tr} A$ operon in $S$. solfataricus contains a second gene encoding a putative membrane protein, of which a homolog ( $27 \%$ sequence identity on protein level) is encoded on a distant genomic location in S. acidocaldarius (Saci_2078, Figure 1A).

Sequence comparison with representatives of the different YtrA subfamilies in actinomycetes revealed a clear similarity between YtrA $\mathrm{S}_{\mathrm{Sa}}$ and the subfamily of YtrA-like TFs in S. coelicolor that are encoded in an operon with a gene encoding a membrane protein instead of genes coding for an $\mathrm{ABC}$ transport system (Figure 1B). The length of the putative $\alpha$-helix $\alpha 4$ in the C-terminal domain is a major difference between the Sulfolobales orthologs and S. coelicolor SCO3812 on one hand and other YtrA-like proteins that are co-encoded with an ABC transporter operon. This is predicted to be 4-7 amino acids shorter for the former as compared to YtrA homologs from the Euryarchaeote Thermoplasma acidophilum and from the bacteria B. subtilis and C. glutamicum. Furthermore, for all YtrA proteins, sequence conservation is much lower in the C-terminal E-O domain than in the N-terminal DNA-binding domain (Figure 1B).

\section{Genome-Wide Interactions Between YtrA $_{\text {Sa }}$ and DNA in vivo}

As an effort to reveal genomic binding sites of YtrA $\mathrm{Sa}_{\mathrm{S}}$, a ChIPseq experiment was performed using polyclonal anti-YtrAsa 

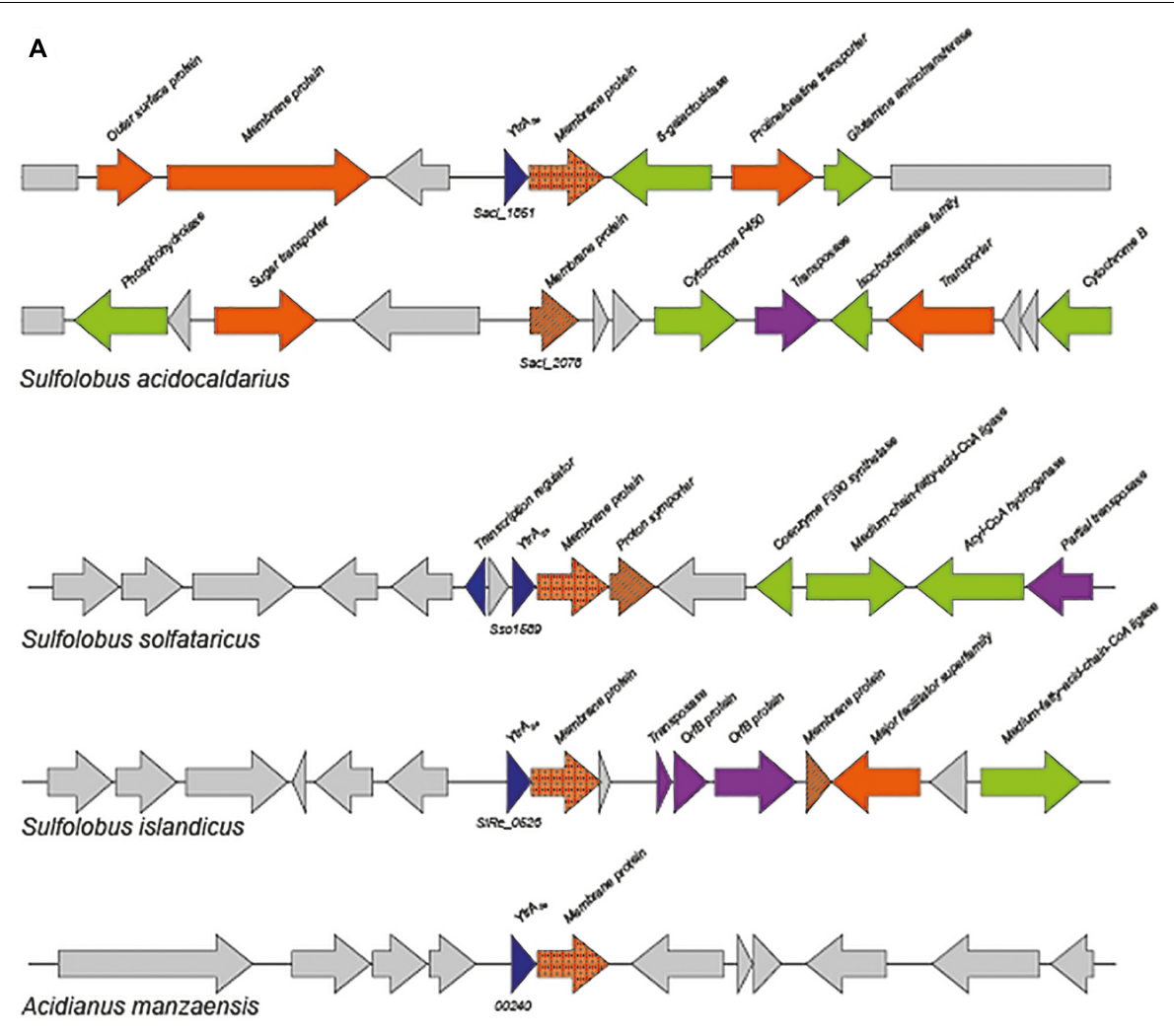

Acidianus manzaensis

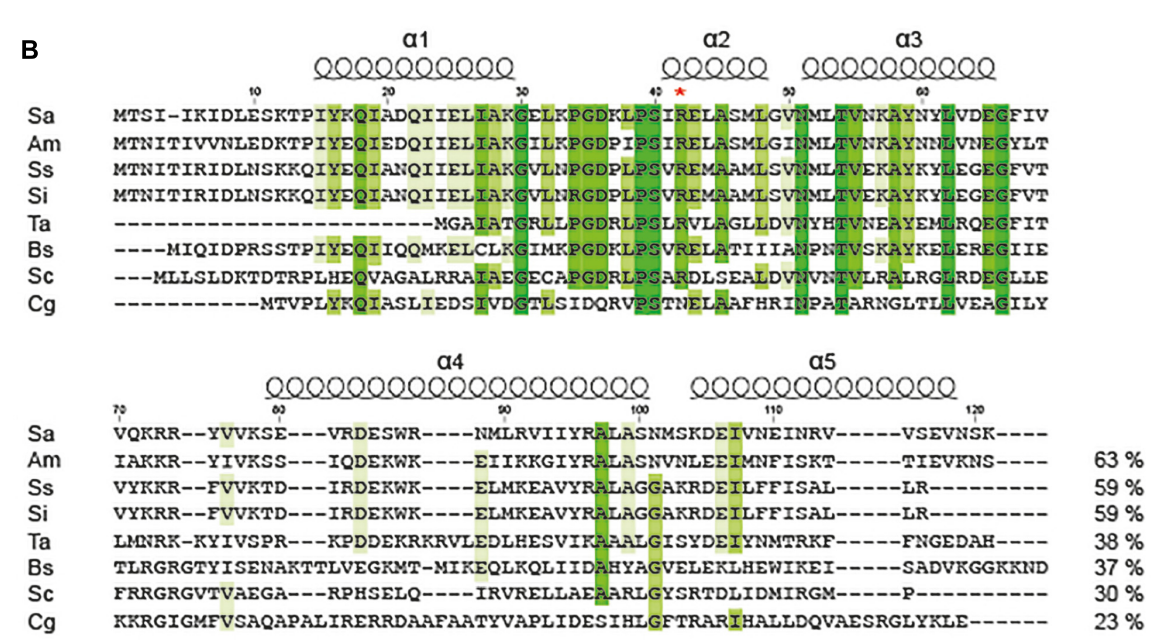

FIGURE 1 | Sulfolobales genomes encode a YtrA-like homolog. (A) Genomic organization of ytrA-like genes in Sulfolobales. Gene functions are mentioned based on annotations (Chan et al., 2012) with the following color code: blue, (putative) transcription regulators; orange, (putative) membrane proteins and/or transporters; green, (putative) metabolic enzymes; purple, (putative) transposon-associated functions. All Sulfolobales strains of which genome sequences are present in the SyntTax database (Oberto, 2013) harbor a ytrA homolog. The strains represented in the scheme are Sulfolobus acidocaldarius DSM639, Sulfolobus solfataricus P2, Sulfolobus islandicus REY15A and Acidianus manzaensis YN25. (B) Sequence alignment of YtrA-like GntR-family regulators in archaea and bacteria. Following sequences are shown in the alignment: Q4J7S4 Sulfolobus acidocaldarius (Sa), AOA1W6JWH0 Acidianus manzaensis (Am), Q97XX0 Sulfolobus solfataricus (Ss), F0NDQ3 Sulfolobus islandicus (Si), Q9HK68 Thermoplasma acidophilum (Ta), O34712 Bacillus subtilis (Bs), Q9XA65 Streptomyces coelicolor (Sc), Q8NLJ5 Corynebacterium glutamicum (Cg). Conserved amino acid residues are indicated in shades of green. Sequence identities are provided next to each sequence. Position numbers are indicated with respect to YtrAsa, while secondary structure elements are displayed based on the crystal structure of the C. glutamicum YtrA (PDB:2EK5) (Gao et al., 2007). A red asterisk denotes an Arg that is presumed to play an important role in DNA binding.

antibodies (Figure 2 and Table 1). The resulting binding profile consisted of only two highly enriched regions with an average fold enrichment of 24.3 and 113.5 for peak 1 and 2, respectively.
The first enriched peak (peak 1) corresponds to a 750-bp region covering the promoter region of the operon encoding the TF itself and a putative membrane protein (Saci_1851 and Saci_1850, 


\section{A}

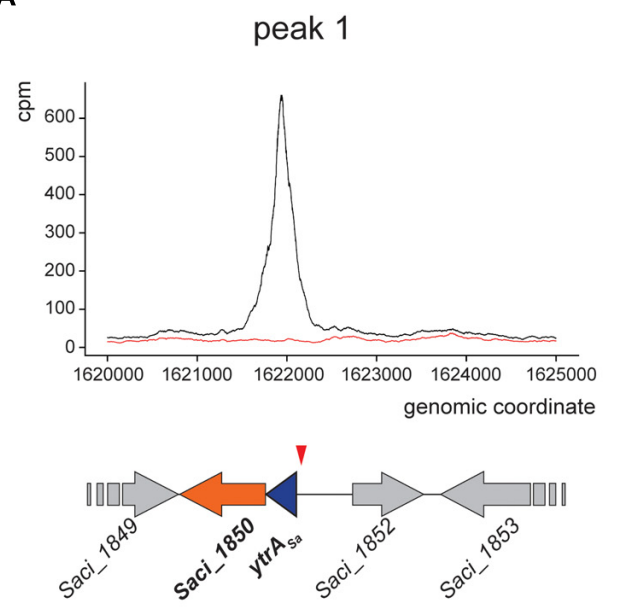

peak 2

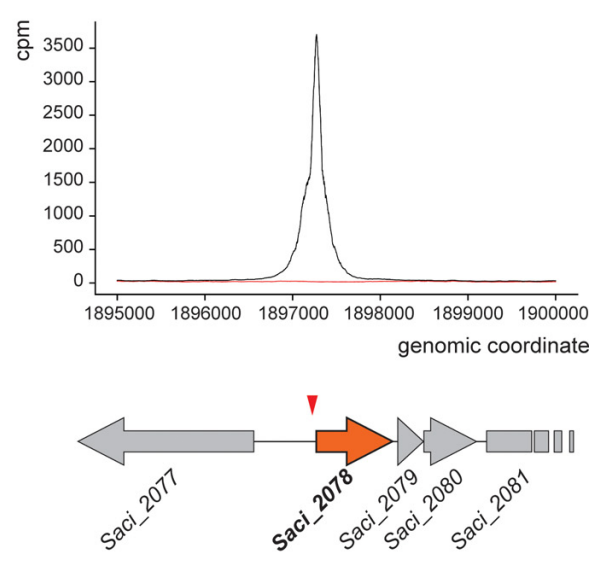

B

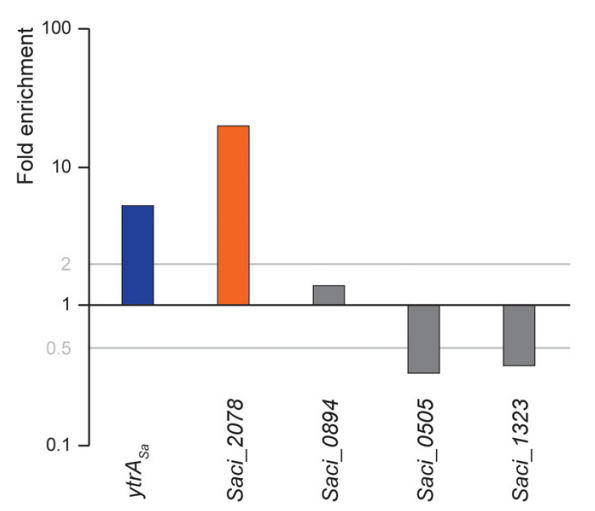

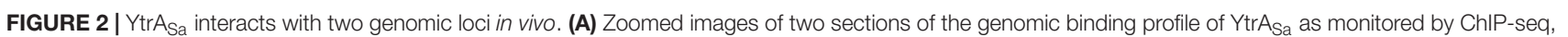
for which enrichment was observed. Below the profile, a schematic representation of the genomic organization of the in vivo binding regions is shown with the indication of the ChIP-seq peak summit locations (red triangle). The black curve represents the ChIP sample, while the red curve represents the mock experiment; $\mathrm{cpm}$ = counts per million. (B) Validation of ChIP enrichment using a qPCR approach with probes designed based on the detected binding region in ChIP-seq (targets are named after the gene located closest in the neighborhood). This experiment has been performed for biological triplicates, with the data shown being representative for all replicate experiments. Fold enrichment is expressed relative to a genomic region within the ORF of Saci_1336 shown not to be bound by YtrA in the genome-wide ChIP-seq experiment.

respectively) with its summit located close to the transcriptional start of the operon (Figure 2A). A second enriched region of about 800 bp was observed in the intergenic region upstream of another putative membrane protein-encoding gene (Saci_2078). Interestingly, this gene was predicted to be homologous to the second membrane protein-encoding gene in the S. solfataricus and $S$. islandicus ytrA operons (see above). Similar to peak 1, its summit is located close to the transcriptional start site. Observed enrichments were validated by targeted ChIP-qPCR (Figure 2B). Both qPCR and high-throughput sequencing displayed a higher enrichment for the Saci_2078 target (peak 2) than for the Saci_1851 $\left(y \operatorname{tr} A_{S a}\right)$ target (peak 1) (targets are named after the gene located closest to the bound genomic region). Besides the two main targets, three additional genomic regions (Saci_0884, Saci_0505 and Saci_1323 targets) were enriched by ChIP-seq in some, but not all biological replicates. This was not confirmed by ChIP-qPCR (Figure 2B). In conclusion, these data suggest that the $\mathrm{Ytr}_{\mathrm{Sa}}$ direct regulon is very restricted and limited to only two target regions upstream of genes encoding membrane proteins.

\section{In vitro Analysis of YtrAsa-DNA Interactions}

For both ChIP-seq enriched regions, electrophoretic mobility shift assays (EMSAs) were performed using purified $Y_{\operatorname{tr}} \mathrm{A}_{\mathrm{Sa}}$ protein and labeled DNA probes of about 100 bp each encompassing the center of a ChIP-seq peak (Figure 3). These assays demonstrated high-affinity and specific interactions of YtrA $_{S a}$ with the DNA in vitro, resulting in the formation of two electrophoretically distinct complexes (B1 and B2) at relatively low protein concentrations (between 17 and $230 \mathrm{nM}$ ). The observation of a transient formation of complex B1 at low relative abundances suggests that the interaction is characterized by a positive binding cooperativity, which is corroborated by 
TABLE 1 | Summary of ChIP-seq results.

\begin{tabular}{|c|c|c|c|c|c|c|}
\hline \multirow{2}{*}{$\begin{array}{l}\text { Peak interval } \\
\text { (genomic } \\
\text { coordinates) }\end{array}$} & \multicolumn{3}{|c|}{ Fold enrichment } & \multirow{2}{*}{$\begin{array}{l}\text { Nearest } \\
\text { open } \\
\text { reading } \\
\text { frame }\end{array}$} & \multirow[t]{2}{*}{ Annotation } & \multirow{2}{*}{$\begin{array}{l}\text { Peak } \\
\text { summit } \\
\text { location }\end{array}$} \\
\hline & R1 & $\mathbf{R} 2$ & R3 & & & \\
\hline $\begin{array}{l}1897151- \\
1897397\end{array}$ & 133.2 & 96.30 & 108.0 & $y \operatorname{tr} A_{S a}$ & $\begin{array}{l}\text { GntR family } \\
\text { transcriptional } \\
\text { regulator }\end{array}$ & 1 \\
\hline $\begin{array}{l}1621827- \\
1622073\end{array}$ & 30.89 & 23.72 & 17.01 & Saci_2078 & $\begin{array}{l}\text { Membrane } \\
\text { protein }\end{array}$ & 1 \\
\hline $\begin{array}{l}718252- \\
718538\end{array}$ & 7.05 & 4.64 & N.S. & Saci_0894 & $\begin{array}{l}\text { Hypothetical } \\
\text { protein }\end{array}$ & $G$ \\
\hline $\begin{array}{l}419146- \\
419392\end{array}$ & 4.73 & N.S. & N.S. & Saci_0505 & $\begin{array}{l}\text { Conjugative } \\
\text { plasmid } \\
\text { protein }\end{array}$ & I \\
\hline $\begin{array}{l}1130433- \\
1130685\end{array}$ & N.S. & N.S. & 6.47 & Saci_1323 & $\begin{array}{l}\text { Hypothetical } \\
\text { protein }\end{array}$ & I \\
\hline
\end{tabular}

Fold-enrichments are expressed for three replicate experiments $(R 1, R 2$, and R3). It is indicated whether the peak summit is located on an intergenic (I) or intragenic (G) location.

densitometric analysis of EMSA autoradiographs resulting in Hill coefficients of 2.3 and 2.6 for the $y \operatorname{tr} A_{S a}$ and Saci_2078 targets, respectively. Furthermore, apparent dissociation constants $\mathrm{K}_{\text {Dapp }}$ are estimated to be 37 and $34 \mathrm{nM}$, respectively (Figure 3). Quantitative and qualitative binding characteristics are thus very similar for both target regions, in contrast to the in vivo binding characteristics as observed by the ChIP enrichments.

Subsequently, DNase I footprinting was performed to delineate the exact binding regions (Figure 4A). Binding of $\mathrm{YtrA}_{\mathrm{Sa}}$ resulted in similarly sized protected regions of 34 and 35 nucleotides (nt) for the $y \operatorname{tr} A_{S a}$ and Saci_2078 targets, respectively. In addition, for both targets hypersensitivity effects were observed that indicate an increased susceptibility to DNase I digestion upon protein binding localized in one or both outer halves of the protected regions. Nucleotides that are typified by such hypersensitivity effects become more exposed to DNase I digestion through protein-induced deformations that widen the minor groove. It can thus be concluded that YtrA $\mathrm{A}_{\mathrm{Sa}}$ causes a DNA bending upon interacting with its binding sites. Both binding sites have a remarkably similar location with respect to transcriptional elements in the promoter: they are located downstream of the factor B recognition element (BRE) and TATA box elements, but cover the transcription initiation site, with the respective transcription start sites (TSSs) being positioned in the center of the binding regions (Figure 4A). Locational conservation of sequence-specific YtrA $\mathrm{A}_{\mathrm{Sa}}$ operator sites was confirmed upon aligning both promoter region sequences, with the protected regions being characterized by a high sequence identity, which is not apparent for the up- and downstream regions, with the exception of two conserved TA bps in the TATA box element (Figure 4B).

\section{Definition of a YtrAsa Binding Motif}

Upon identifying binding sites with DNase I footprinting, it was apparent that these contained palindromic residues. To further investigate the exact nature of the recognized inverted repeat, a phylogenetic in silico footprinting analysis was performed using the corresponding binding sites of (putative) targets in Sulfolobales species that contain a YtrAsa homolog (Figure 5A). A 32-bp inverted repeat was delineated, in which different submotifs could be discerned: a 14-bp core binding motif (primary motif) with two highly conserved palindromic half sites (Left $_{\text {prim }}$ and Right $t_{\text {prim }}$ ) and a center that is rich in weak bp (Middle $_{\text {prim }}$ ). On each side of the core binding motif, additional partial sites (secondary motif) were observed with a weaker conserved 3-bp semi-palindromic sequence that corresponds to the "left" and "right" half-sites of the core binding motif $\left(\right.$ Left $_{s e c}$ and Right $s e c$ ). EMSAs with 50-bp mutated variants of the $y \operatorname{tr} A_{S a}$ binding motif demonstrated that each of the submotifs contributes to binding (Figures 5B,C). When mutating all primary submotifs (Left prim, Right $_{\text {prim }}$ and Middle prim $_{\text {) }}$ (MUT A), YtrA $\mathrm{Aa}_{\mathrm{Sa}}$ binding was almost entirely abrogated, confirming the essentiality of the primary motif as a core binding site. In this core motif, the highly conserved half sites contribute more to binding affinity than the weak-bp center (compare MUT B to MUT C). Finally, as the simultaneous mutation of the secondary half sites (Middle ${ }_{\text {sec }}$ ) on both sides of the core binding motif (MUT D) also resulted in a strong decrease in binding affinity, a role for these secondary half sites was confirmed as well (Figure 5C).

Based on the characterized 14-bp core palindromic motif, the $S$. acidocaldarius genome was screened for additional occurrences of this binding motif, restricted to 500-bp stretches upstream of annotated ORFs (Supplementary Table S4). Several additional putative binding motif sequences were retrieved, of which two have similar $P$-values as the originally identified $Y \operatorname{tr} A_{S a}$ binding sites in the Saci_2078 promoter region (between $1.0 \mathrm{e}^{-06}$ and $1.0 \mathrm{e}^{-05}$ ) and have an identical positioning with respect to the translational start codon by completely covering it. These binding motifs are located in the control region of Saci_1073 encoding another membrane protein and Saci_1554 encoding a ribosomal protein. However, analysis by EMSA and ChIPqPCR demonstrated that neither high-affinity in vitro binding nor in vivo binding is observed for YtrASa (Supplementary Table S4). This might be explained by a lack of conservation of secondary half sites accompanying the identified primary binding motif (Supplementary Figure S3) and suggests that these sites, given their ideal location to exert regulation and their well-conserved core motif, are either remnants of YtrAsa regulatory events that took place earlier in evolution or are targets of an alternative transcription factor with a similar DNAbinding specificity. These results confirm the restricted binding profile of YtrA $A_{S a}$ in the $S$. acidocaldarius genome as was revealed by ChIP-seq.

\section{Three-Dimensional Structure of YtrAsa}

A crystallographic analysis of YtrA $A_{S a}$ yielded a structure at $3.0 \AA$ resolution (Figure 6). The $14-\mathrm{kDa} \mathrm{YtrA}_{\mathrm{Sa}}$ protein crystallized as a dimer with the asymmetric unit of the crystal structure containing a homodimer with an exclusive $\alpha$-helical structure. Each monomeric unit displays an N-terminal DNA-binding domain harboring the typical GntR-like wHTH motif $(\alpha 1-\alpha 3)$ and a short C-terminal E-O domain, consisting of two $\alpha$ helices $(\alpha 4-\alpha 5)$ that mediate dimerization, which is a typical feature for YtrA-like regulators. 

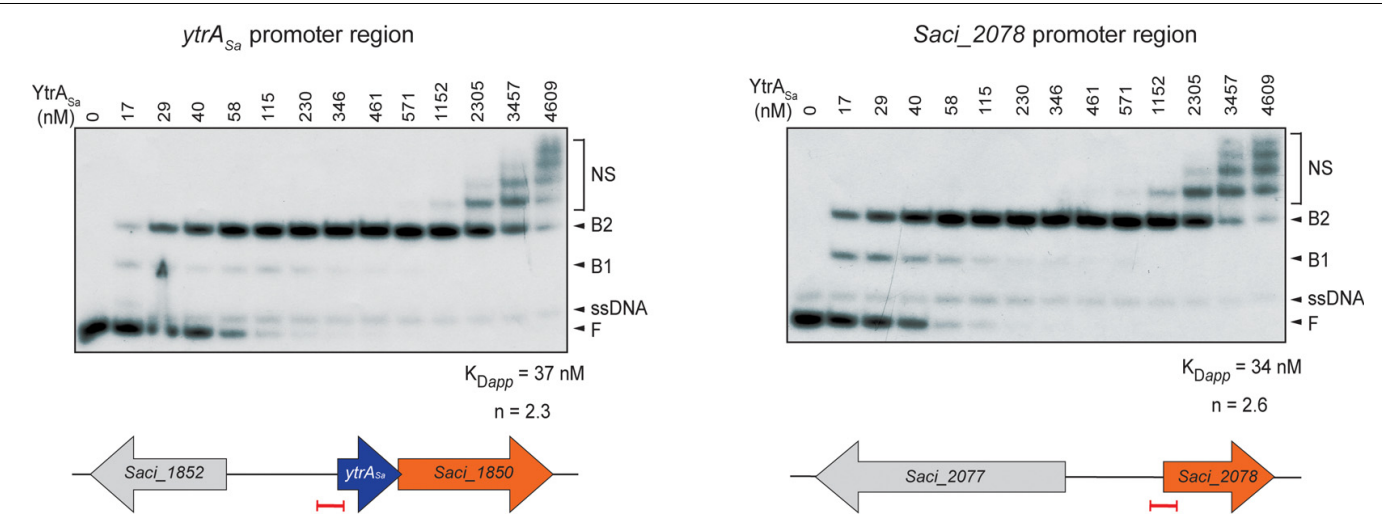

FIGURE 3 | YtrAsa forms complexes with its DNA targets in vitro and with high affinity. Electrophoretic mobility shift assays (EMSAs) of YtrAsa binding to radiolabeled DNA probes of about $100 \mathrm{bp}$ representing the ChIP-seq peaks. Molar protein concentrations are indicated above the autoradiograph. Populations of free DNA (F),

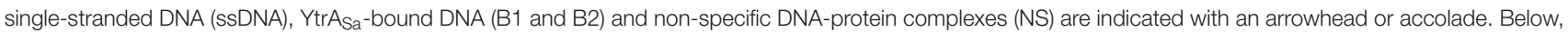
schematic representations are shown of the location of the probe (indicated in red) used in EMSA with respect to the open reading frames (ORFs) in the genomic neighborhood of the target regions. Calculations of apparent dissociation constants $\left(\mathrm{K}_{\mathrm{Dapp}}\right)$ and Hill coefficients $(\mathrm{n})$ are based on densitometric analysis of free DNA bands followed by binding curve analysis.

Upon comparing the $\mathrm{Ytr}_{\mathrm{Sa}}$ structure with that of the only described bacterial YtrA-type crystal structure, CGL2947 of C. glutamicum (Gao et al., 2007), major structural differences are observed despite the similar topological organization (Figure 6A). The distance between the two monomeric Arg42 residues, located in wHTH domain, amounts $36 \AA$, which is similar to the length of one turn of the DNA helix. This is only about half of the distance between corresponding monomeric residues in the C. glutamicum YtrA structure (Figure 6A inset). This structural difference can be ascribed to the length of the a4 helix, which is shorter for the YtrA subfamily of which the gene is colocalized in an operon with a gene encoding a membrane protein, consisting of the Sulfolobus YtrA homologs and S. coelicolor SCO3812.

For one of the $Y_{t r A} A_{S a}$ chains, the $\alpha 5$ helix could not be modeled due to poor electron density, likely explained by a flexible behavior of these C-terminal helices within the crystal. Furthermore, the alignment of individual monomeric chains from within the same dimer demonstrated that the $\mathrm{E}-\mathrm{O}$ domain has an asymmetric nature (Figure 6B). Although these observations might be ascribed to the crystal packing and are not necessarily biologically relevant, the short length of a4 underlies a compact E-O domain regardless of its exact conformation and a shorter distance between the two monomeric DNA-binding domains in comparison to other YtrAlike regulators.

\section{Determination of the YtrAsa Regulon}

To study the effect of $Y_{t r} A_{S a}$ on the transcriptional expression of its target genes, a $y \operatorname{tr} A_{S a}$ overexpression strain was constructed (Supplementary Figure S1) and subjected to a comparative transcriptomic analysis using an RNA-Seq approach, followed by validation with RT-qPCR (Figure 7 and Supplementary Table S5). This analysis revealed 12 differentially expressed genes, including the $y t r A_{S a}$ gene itself, which showed a strong upregulation in the overexpression strain, as expected.
Both membrane-protein encoding genes that are targeted by $\mathrm{YtrA}_{\mathrm{Sa}}$ for high-affinity binding, Saci_1850 and Saci_2078, were found to be significantly downregulated in the $y \operatorname{tr} A_{S a}$ overexpression strain suggesting a role as a transcriptional repressor for $\mathrm{Ytr}_{\mathrm{S}}$.

All other genes that displayed differential expression in the $y \operatorname{tr} A_{S a}$ overexpression strain, either a higher or lower expression level (Figure 7), were shown not to harbor a $\mathrm{Ytr} \mathrm{A}_{\mathrm{Sa}}$ binding motif in their promoter region (Supplementary Table S4). In addition, their promoter regions did not show an interaction with $\mathrm{YtrA}_{\mathrm{Sa}}$ in vivo or in vitro (Table 1, data not shown). Their differential expression can thus be explained by indirect regulatory effects. These genes belong to a variety of functional categories, such as a conjugative plasmid protein (Saci_0484), a sulfite oxidoreductase (Saci_1202), an acetylCoA C-acyltransferase (Saci_2233), encoded in an operon with other acyltransferase-encoding genes, and a predicted 4hydroxyphenylacetate 3-hydroxylase (Saci_2294) and catechol 2,3-dioxygenase (Saci_2295), co-encoded in an operon and involved in the oxidative degradation of aromatic compounds. Analysis by RT-qPCR confirmed a slightly lower expression level for the Saci_2230-Saci_2233 and Saci2293-Saci_2295 operons and the sulfite oxidoreductase-encoding Saci_0484, but not for the other genes (Figure 7). It can thus be concluded that $\mathrm{YtrA}_{\mathrm{Sa}}$ is a repressor of a restricted regulon, consisting of only two genes encoding putative membrane proteins, of which the function is unknown. Sequence analysis did not reveal any homologies to characterized membrane proteins or transporters. Possibly, these targets are transporter proteins of which the physiological function is linked to the metabolic functions of enzymes encoded by the indirectly regulated operons, such as degradation of aromatic compounds. To test this hypothesis, the effect of six aromatic compounds (phenol, catechol, biphenyl, phenylacetyl-CoA, salicylate and benzaldehyde) on the in vitro binding of $\mathrm{YtrA}_{\mathrm{Sa}}$ to the promotor region of its own operon was analyzed by EMSA (Supplementary Figure S4). None of 
A $y \operatorname{tr} A_{\mathrm{Sa}}$ promoter region

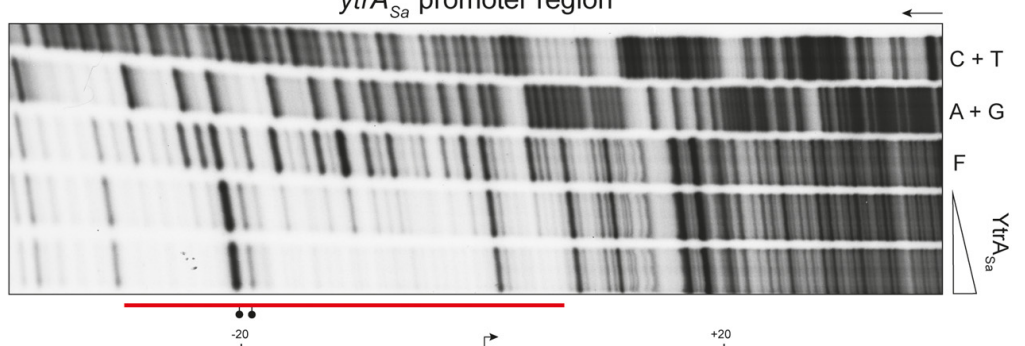

TAAATAAGGTTTTTATTCCCCTAA ATCATATATTTGCTATATGACAAGTATAATAAAA'́ATCGACCTAGAGTCCAAGACTCCCATC ATTTATTCCAAAAATAAGGGGATTPAGTATATAAACGATATACTGTTCATATTATTITTMGCTGGATCTCAGGTTCTGAGGGTAG BRE TATA box $\overrightarrow{y t r A}_{S a}$

Saci_2078 promoter region

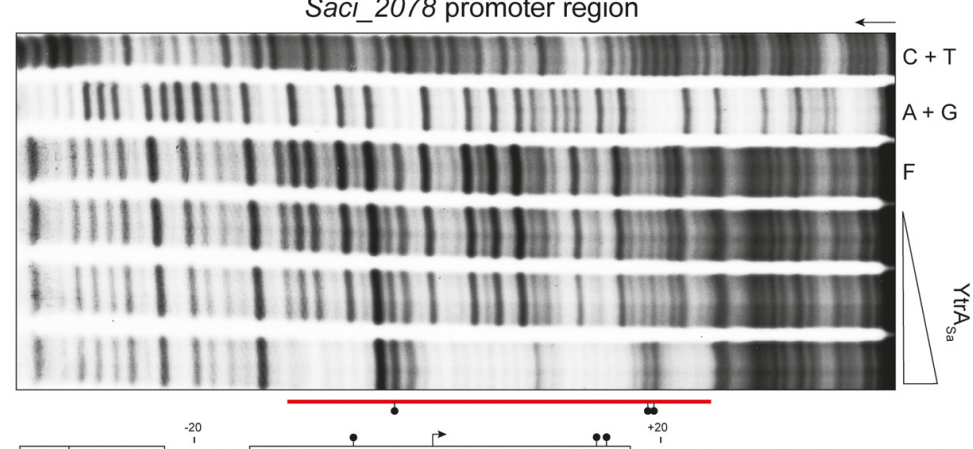

GCCATAACTTTAAATAAGGATAPTGTTATATTTGTTATATGACAAATATGTTTTCATTACTCTACCACTCTACCCGCTAATCTCC CGGTATTGAAATTTATTCCTATAACAATATAAACAATATACTGTTTATACAAAAGTAATGAGATGGTGAGATGGGCGATTAGAGG BRE TATAbox $\overrightarrow{\text { Saci_}} 2078$

B

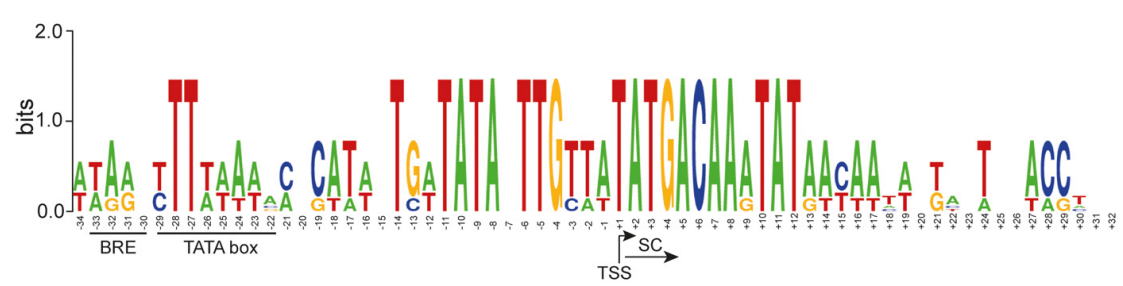

FIGURE 4 | YtrAsa binds a conserved binding motif covering the transcriptional start for both targets. (A) Autoradiographs of DNase I footprinting experiments performed with 102- or 100-bp DNA probes having either the bottom (ytrA $A_{S a}$ target) or top (Saci_2078 target) strand ${ }^{32} \mathrm{P}$-labeled, respectively. Arrows indicate the direction of electrophoresis; "A + G" and "C + T" represent the purine- and pyrimidine-specific Maxam-Gilbert sequencing ladders, respectively; " $F$ " denotes the population of free DNA; the other lanes show samples to which $Y_{t r} A_{S a}$ protein was added at the following concentration range: $40-571 \mathrm{nM}$ for the $y t r A_{S a}$ target and 40-230 nM for the Saci_2078 target. Protected zones are indicated with a horizontal red line, while DNase I hypersensitivity sites are pointed out with ball-and-sticks symbols. Conserved binding motifs are boxed. Below each autoradiograph, the corresponding nucleotide sequence is shown with annotation of the observed protection zone (red letters) and hypersensitivity sites (ball-and-stick symbols). The translational start codon is indicated with an arrow below the sequence, while the transcription start site (TSS) is pointed out with an arrow above the sequence. The TSS of $y t r A_{S a}$ is based on a high-resolution transcriptome database (Cohen et al., 2016), while that of Saci_2078 is predicted based on sequence alignment of both promoter regions. Putative factor B recognition element (BRE) and TATA box promoter elements are boxed. (B) Sequence logo representation of a nucleotide sequence alignment of both target promoter regions, with indication of BRE, TATA box, start codon (SC) and TSS.

the compounds affected the YtrA $\mathrm{A}_{\mathrm{Sa}}$-DNA binding and a YrtA ligand is thus not identified.

\section{DISCUSSION}

YtrA $_{S a}$ performs an (auto-)repression function by interacting with high specificity and affinity with a 32-bp long inverted repeat. However, the following indications suggest that the formed YtrAsa-DNA complex minimally consists of a single protein dimer that mainly establishes contacts with a core region of $14 \mathrm{bp}$, the primary binding motif: (i) protein binding assays with mutant variants of the binding site demonstrate that the primary motif is essential (Figure 5); (ii) the crystallographic dimeric structure of $\mathrm{YtrA}_{\mathrm{Sa}}$ is in line with the recognition of a 14bp binding motif, given the compact structure and corresponding residues in the two $\mathrm{wHTH}$ motifs being separated by a distance that roughly amounts to a single turn of the DNA helix (36 ̊) (Figure 6A). A hypothetical model of the YtrA $\mathrm{Sa}_{\mathrm{a}}$-DNA complex shows that in such a conformation, the dimer interacts with 
A

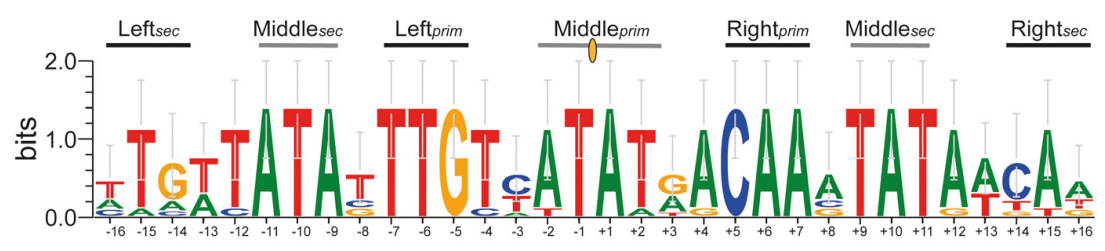

B

WT

MUT A

TATTCСССТАААTCATATATTTGCTATATGACAAGTATAATAAAAATCGACCTA

Ls Ms Lp Mp Rp Ms Rs

MUT B

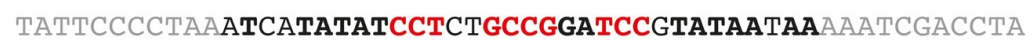

MUT C

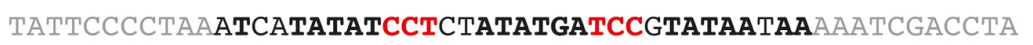

MUT D

TATTССССТААТСАTATATTTGCTGCCGGACAAGTATAATAAAАATCGACCTA

TATTCCCCTAАATCAGCGCTTTGCTATATGACAAGGCGCATAAAAATCGACCTA

C

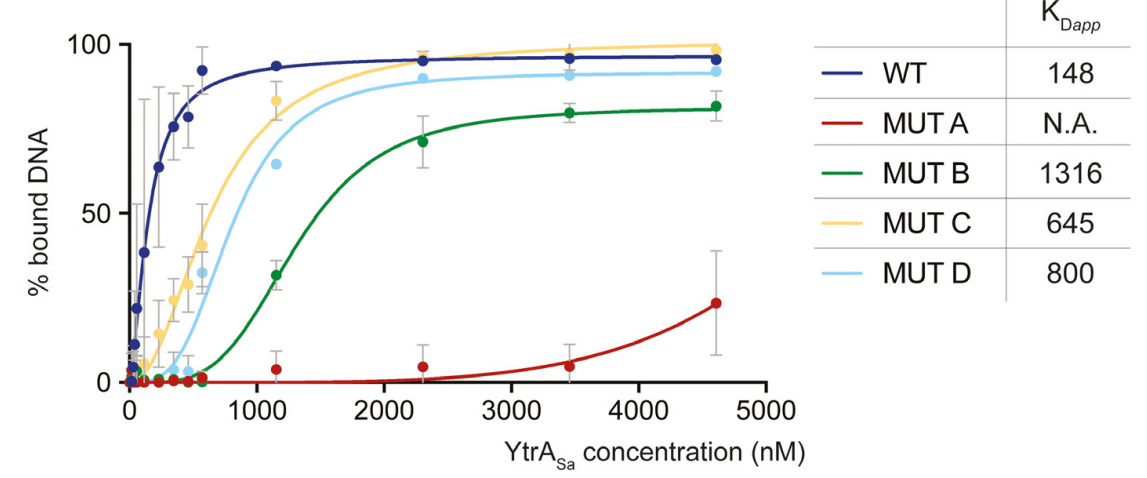

FIGURE 5 | Palindromic elements in the binding motif that support $Y_{t r} A_{S a}$ interaction as shown by mutational analysis. (A) Sequence logo depicting a phylogenetic footprint using the forward and reverse sequences of the conserved YtrA binding motif identified in the ytrA promoter regions of $S$. acidocaldarius, S. solfataricus, S. islandicus and A. manzaensis and in the Saci_2078 promoter region of S. acidocaldarius. Primary (prim) and secondary (sec) binding motif elements are indicated. The center of dyad symmetry is annotated with a yellow oval symbol. (B) Overview of the experimental design of mutated binding site variants (MUT), with the wild type (WT) binding site of the $y t r A_{S a}$ target as a starting point. Palindromic residues are depicted in bold and mutated residues in red. (C) Graphical representation of binding curve analysis based on densitometric analysis of electrophoretic mobility shift assays performed with 50-bp DNA probes containing binding site variants as presented in panel B. Averages of calculated apparent equilibrium dissociation constants $\left(K_{D a p p}\right)$ are shown as well for each of the variants. Experiments were performed in duplicate. $\mathrm{K}_{\text {Dapp }}$ discrepancies for the 50-bp WT probe used in this experiment and the 102-bp probe used in the initial EMSA experiment shown in Figure $\mathbf{3}$ can be explained by the differing length, which affects binding affinity (Peeters et al., 2007).

two major groove segments and the intervening minor groove segment (Figure 8).

Sequence-specific amino acid-nucleotide interactions are presumed to take place in the major grooves that contain palindromic half sites with highly conserved bp residues, while the center of the binding motif faces with the minor groove toward the regulator and contains weak bp that facilitate protein-induced bending. In this model, the highly conserved Arg42 is ideally positioned for base-specific interactions with the symmetrical GC and CG bp in the palindromic half sites (Figure 8). This interaction is likely to occur since for bacterial YtrA-like regulators a correlation has been observed between the corresponding Arg residue and strong bp (Suvorova et al., 2015). Furthermore, an Arg interaction with GC/CG bp is known to account for a large fraction of specific protein-DNA contacts (Marabotti et al., 2008) and also occurs in FadR and HutC subfamilies of GntR TFs (Suvorova et al., 2015). This empowers our hypothesis that the half-sites in the central 14-bp motif are contacted in the major groove with the establishment of sequence-specific interactions. Interestingly, in contrast to canonical wHTH-containing DNA-binding proteins (Aravind et al., 2005), it is not the recognition helix $\alpha 3$ that is presumed to dock into the major groove and establish contacts with the DNA, but instead the preceding $\alpha 2$, which also contains the conserved Arg42 hypothesized to be involved in base-specific contacts. Indeed, the YtrA $\mathrm{A}_{\mathrm{Sa}}$ structure demonstrates a relative orientation of the $\alpha 3$ helices that precludes a potential involvement in direct DNA interactions (Figure 6).

A binding mode with a dimer interacting with a 14-bp binding motif with two-fold symmetry is often observed for prokaryotic 

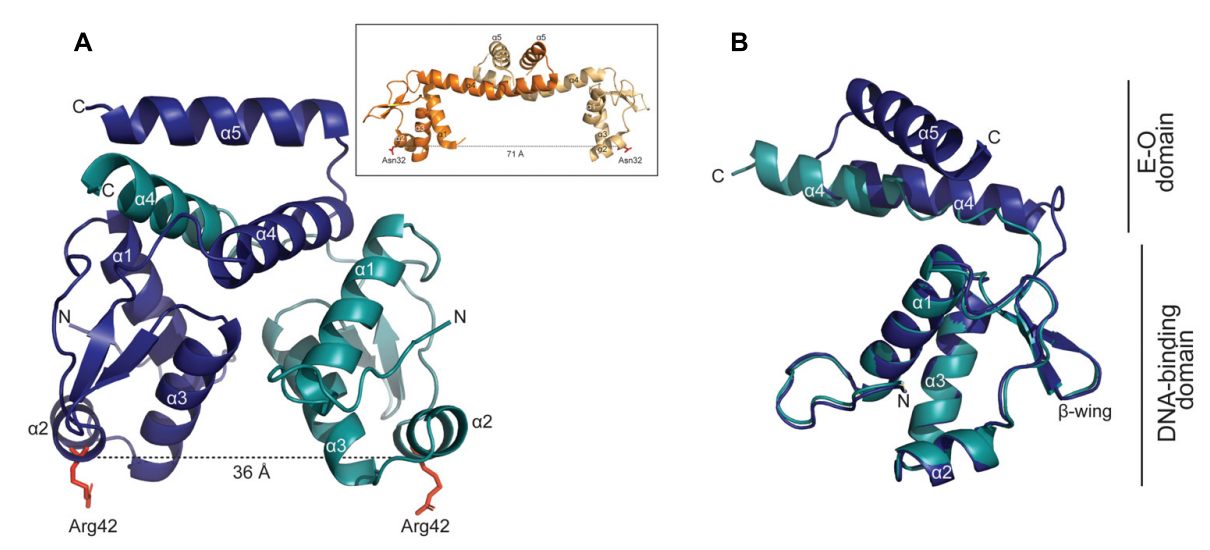

FIGURE 6 | YtrA $\mathrm{Sa}_{\mathrm{Sa}}$ has a dimeric structure with a distance of $36 \AA$ between the DNA-binding domains. (A) Crystallographic structure of the YtrA $\mathrm{Sa}$ dimer with indication of the different chains in different colors (chain A: $\alpha 1-5$; chain B: $\alpha 1-4$ ) and the distance between two corresponding $\alpha 2$ residues (Arg42). The $\alpha 5$ helix of chain B could not be modeled due to poor electron density. In the inset, the protein structure of the YtrA-like CGL2947 of Corynebacterium glutamicum is displayed (PDB:2EK5) (Gao et al., 2007) with indication of the distance between conserved $\alpha 2$ residues. (B) Structural alignment of chains A and B of YtrA indication of the different domains.

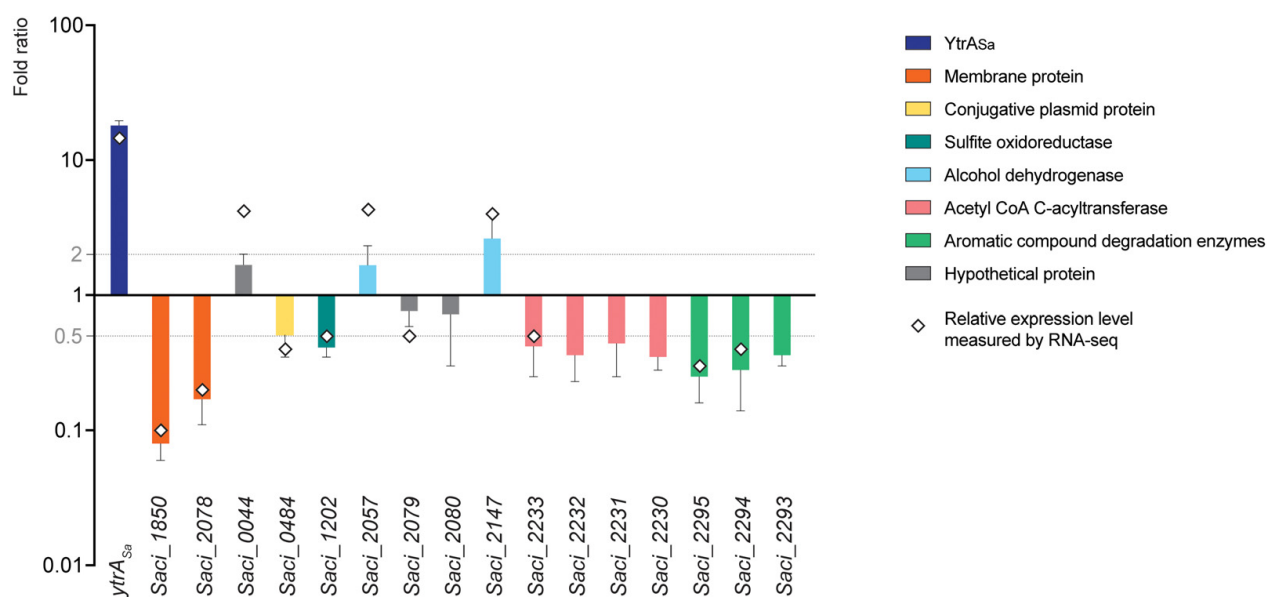

FIGURE 7 | YtrAsa exerts repression on its direct target genes encoding two membrane proteins. A bar plot shows relative gene expression levels as determined by $\mathrm{RT}$-qPCR, comparing a ytrA $A_{S a}$ overexpression strain with its isogenic wild type. Error bars represent the standard deviations of three biological repeats. Average fold-change values of RNA-Seq analysis are depicted by a diamond. Gray lines represent a fold change of 2 and 0.5 , respectively.

TFs, including non-YtrA GntR members (Rigali et al., 2002; Aravind et al., 2005) and contrasts with the typically longer palindromic binding motifs of bacterial YtrA TFs (Rigali et al., 2002), such as the motif GGTG- $\mathrm{N}_{16}$-CACC that is recognized by a YtrA-like regulator from Xanthomonas citri (Zhou et al., 2017). Such a longer inverted repeat is in agreement with the protein structure described for a C. glutamicum YtrA TF, where the distance between the two recognition helices is $62 \AA$, corresponding to about two turns in the DNA helical structure (Gao et al., 2007) (Figure 6A). Aligning $\mathrm{YtrA}_{\mathrm{Sa}}$ with bacterial YtrA-like TFs shows that a shorter $\alpha 4$ helix in the secondary protein structure leads to the more compact protein structure for the YtrA regulators in Crenarchaeota. This shorter $\alpha 4$ helix is also observed for a subgroup of YtrA-like TFs described in Actinomycetes, typically located in an operon encoding a membrane protein instead of an $\mathrm{ABC}$ transport system (Tsypik et al., 2016). Although no protein structure has been characterized for this subgroup of bacterial YtrA-like regulators, we can assume that they are structurally similar to the $\operatorname{archaeal} \mathrm{Ytr}_{\mathrm{Sa}}$ shown in this work. Furthermore, given that they are both (presumed to be) involved in the regulation of a membrane protein, also their functions might be related.

However, what is then the function of the secondary binding sites, located up- and downstream of the core binding motif? These contain direct repeats of each adjacent half site and have been shown to be important for $\mathrm{YtrA}_{\mathrm{Sa}}$ binding as well: they are protected in footprinting experiments (Figure 4A) and have been shown to mediate the high-affinity formation of stable protein-DNA interactions in vitro and in vivo (Figure 5 and Supplementary Figure S3). Possibly, they are involved in recruiting additional $\mathrm{Ytr}_{\mathrm{Sa}}$ molecules, causing an alternative oligomerization of the protein and/or mediating 


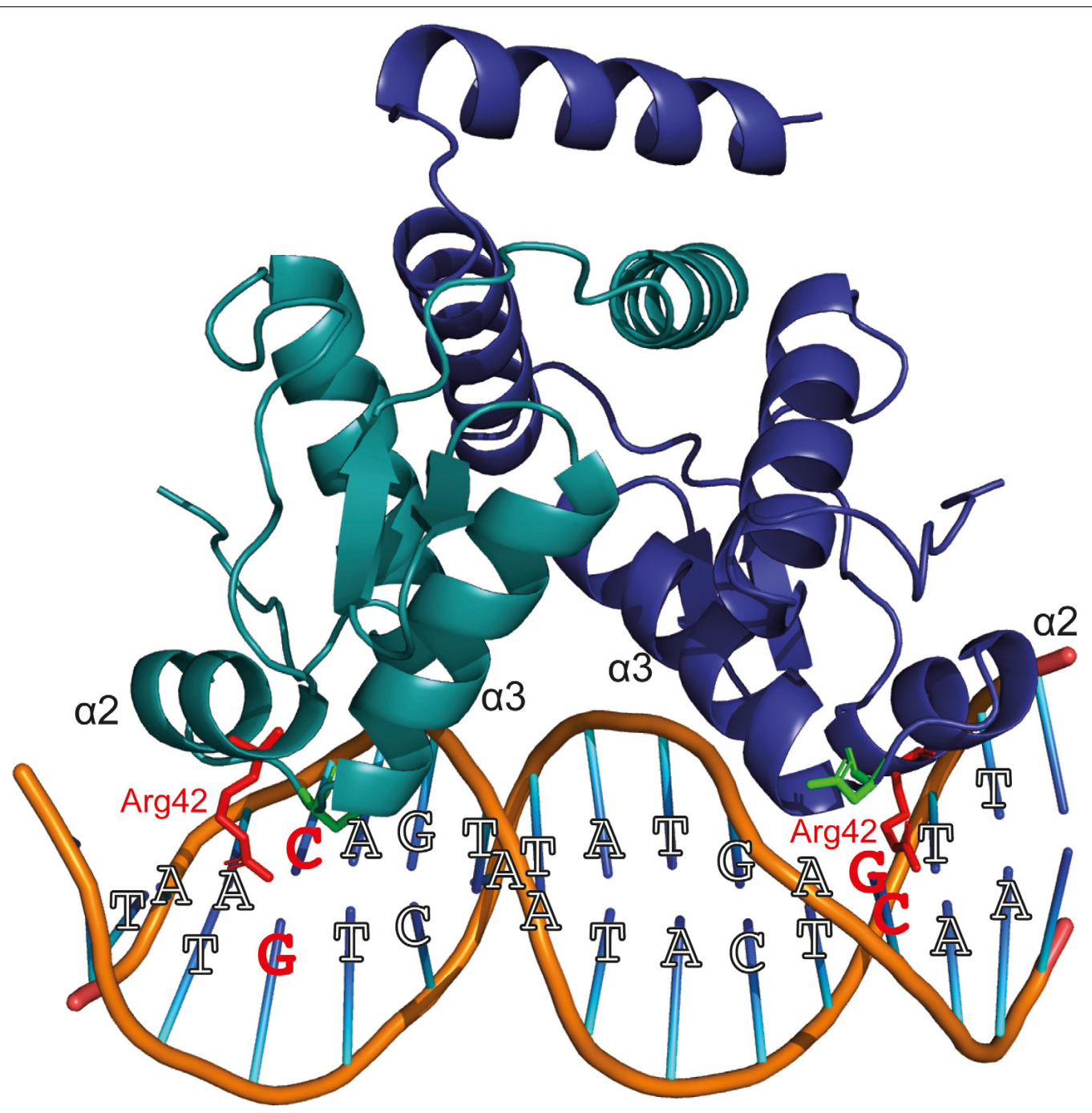

FIGURE 8 | Hypothetical model of protein-DNA interactions that are possibly established when a YtrAsa dimer binds the primary consensus binding motif. This model has been built using Pymol (DeLano, 2002), with indication of the consensus bp and the wHTH helices $\alpha 2$ and $\alpha 3$. Two conserved residues presumed to be important for DNA binding (Suvorova et al., 2015), Arg42 and Asn51, are depicted in a stick representation. The Arg42 residues and GC/CG bp that are hypothesized to interact and to be essential for sequence-specific interaction are colored red.

binding cooperativity (Figure 3). Interestingly, the existence of adjacent weaker half sites accompanying the main binding motif is commonly observed for bacterial GntR-like TFs (Suvorova et al., 2015). Although we hypothesize that the core complex consists of a dimer bound to the 14-bp primary binding motif (Figure 8), the exact stoichiometry of the YtrA $\mathrm{Sa}_{\mathrm{a}}$-DNA complex remains to be determined.

YtrA $_{S a}$ represses the transcription of an operon encoding its own gene and a membrane protein and of a second gene encoding a membrane protein by interacting with a binding site that fully covers the transcription initiation site. This binding site positioning can be presumed to lead to a direct steric hindrance of the recruitment of RNA polymerase, a repression mechanism that has been commonly observed for archaeal repressors (Peeters et al., 2013). YtrA $A_{S a}$ has a very restricted regulon, limited to these membrane proteins, for which we were unable to predict a function. Given the analogy between $\mathrm{Ytr}_{\mathrm{Sa}}$ and the Actinomycetes YtrA subfamily harboring a similarly short $\alpha 4$ helix and being co-encoded with transporter proteins (Tsypik et al., 2016), a transporter function could be hypothesized as well for the target genes of the archaeal YtrA regulators. Based on functions of differentially expressed genes when comparing the $y \operatorname{tr} A_{\text {Sa }}$ overexpression strain with its isogenic wild type, a subset of aromatic compounds as possible ligands was tested in vitro but none influenced the YtrA $\mathrm{Sa}_{\mathrm{S}}$-DNA interaction (Supplementary Figure S4). It is possible that the small E-O domain of $\mathrm{YtrA}_{S a}$ is unable to accommodate ligand binding and only functions for dimerization of the protein as has been predicted previously for YtrA-like regulators (Yoshida et al., 2000; Rigali et al., 2002). Nevertheless, regulation might still be fine-tuned by ligand interaction by an as yet unknown ligand or by post-translational modification. The elucidation of the exact physiological function 
of YtrA $_{S a}$ will require a functional characterization of the regulated membrane proteins.

\section{DATA AVAILABILITY}

The datasets generated for this study can be found in the Gene Expression Omnibus (GSE129464). The crystallographic dataset has been submitted to the Protein Data Bank (PDB: 6SBS).

\section{AUTHOR CONTRIBUTIONS}

LL performed the molecular cloning, protein purification, electrophoretic mobility shift assays, footprinting assays, RNA extractions, chromatin immunoprecipitation assays, qRT-PCR analysis, and data analysis. LT and FN performed the RNA-Seq and ChIP-seq analyses. ED performed the protein purification, electrophoretic mobility shift assays, and footprinting assays. $\mathrm{KV}$ and $\mathrm{A}-\mathrm{CL}$ performed the protein purification and protein crystallography. DM performed the data analysis. EP conceived and designed the study. LL and EP wrote the manuscript.

\section{REFERENCES}

Abramoff, M. D., Magelhães, P. J., and Ram, S. J. (2004). Image processing with image. J. Biophotonics Int. 11, 36-42.

Aravind, L., Anantharaman, V., Balaji, S., Babu, M. M., and Iyer, L. M. (2005). The many faces of the helix-turn-helix domain: transcription regulation and beyond. FEMS Microbiol. Rev. 29, 231-262. doi: 10.1016/j.fmrre.2004.12.008

Bell, S. D., and Jackson, S. P. (2001). Mechanism and regulation of transcription in archaea. Curr. Opin. Microbiol. 4, 208-213. doi: 10.1016/s1369-5274(00)00 190-9

Brock, T. D., Brock, K. M., Belly, R. T., and Weiss, R. L. (1972). Sulfolobus: a new genus of sulfur-oxidizing bacteria living at low $\mathrm{pH}$ and high temperature. Arch. Mikrobiol. 84, 54-68. doi: 10.1007/bf00408082

Chan, P. P., Holmes, A. D., Smith, A. M., Tran, D., and Lowe, T. M. (2012). The UCSC archaeal genome browser: 2012 update. Nucleic Acids Res. 40, D646-D652. doi: 10.1093/nar/gkr990

Chen, L., Brügger, K., Skovgaard, M., Redder, P., She, Q., Torarinsson, E., et al. (2005). The genome of Sulfolobus acidocaldarius, a model organism of the crenarchaeota. J. Bacteriol. 187, 4992-4999. doi: 10.1128/jb.187.14.4992-4999. 2005

Cohen, O., Doron, S., Wurtzel, O., Dar, D., Edelheit, S., Karunker, I., et al. (2016). Comparative transcriptomics across the prokaryotic tree of life. Nucleic Acids Res. 44, W46-W53. doi: 10.1093/nar/gkw394

Crooks, G. E., Hon, G., Chandonia, J.-M., and Brenner, S. E. (2004). WebLogo: a sequence logo generator. Genome Res. 14, 1188-1190. doi: 10.1101/gr.849004

DeLano, W. L. (2002). The PyMOL Molecular Graphics System. San Carlos: Delano Scientific.

Dobin, A., Davis, C. A., Schlesinger, F., Drenkow, J., Zaleski, C., Jha, S., et al. (2013). STAR: ultrafast universal RNA-seq aligner. Bioinformatics 29, 15-21. doi: 10.1093/bioinformatics/bts635

Echols, N., Grosse-Kunstleve, R. W., Afonine, P. V., Bunkoczi, G., Chen, V. B., Headd, J. J., et al. (2012). Graphical tools for macromolecular crystallography in PHENIX. J. Appl. Crystallogr. 45, 581-586. doi: 10.1107/s0021889812017293

Edgar, R. C. (2004). MUSCLE: multiple sequence alignment with high accuracy and high throughput. Nucleic Acids Res. 32, 1792-1797. doi: 10.1093/nar/gkh340

Enoru-Eta, J., Gigot, D., Thia-Toong, T. L., Glansdorff, N., and Charlier, D. (2000). Purification and characterization of Sa-lrp, a DNA-binding protein from the extreme thermoacidophilic archaeon Sulfolobus acidocaldarius homologous to

\section{FUNDING}

Research in the laboratory of EP was supported by the Research Council of the Vrije Universiteit Brussel (start-up funds) and the Research Foundation Flanders (FWO-Vlaanderen) (research project G021118 and research grant $1526418 \mathrm{~N})$. DM received funding from BelSPO (ESA-Prodex AO-2004-070).

\section{ACKNOWLEDGMENTS}

We are grateful to Norio Kurosawa for the generous gift of the S. acidocaldarius SK-1 strain, to Daniël Charlier for assistance with footprinting experiments, to Julie Linussio and David Sybers for help with vector constructions, and to Karl Jonckheere for assistance with protein purification.

\section{SUPPLEMENTARY MATERIAL}

The Supplementary Material for this article can be found online at: https://www.frontiersin.org/articles/10.3389/fmicb. 2019.02084/full\#supplementary-material

the bacterial global transcriptional regulator Lrp. J. Bacteriol. 182, 3661-3672. doi: 10.1128/jb.182.13.3661-3672.2000

Fujita, Y., Fujita, T., Miwa, Y., Nihashi, J., and Aratani, Y. (1986). Organization and transcription of the gluconate operon, gnt, of Bacillus subtilis. J. Biol. Chem. 261, 13744-13753.

Gao, Y.-G., Yao, M., Itou, H., Zhou, Y., and Tanaka, I. (2007). The structures of transcription factor CGL2947 from Corynebacterium glutamicum in two crystal forms: a novel homodimer assembling and the implication for effector-binding mode. Protein Sci. 16, 1878-1886. doi: 10.1110/ps.072976907

Haydon, D. J., and Guest, J. R. (1991). A new family of bacterial regulatory proteins. FEMS Microbiol. Lett. 63, 291-295. doi: 10.1016/0378-1097(91)90 $101-\mathrm{f}$

Heinz, S., Benner, C., Spann, N., Bertolino, E., Lin, Y. C., Laslo, P., et al. (2010). Simple combinations of lineage-determining transcription factors prime cisregulatory elements required for macrophage and B cell identities. Mol. Cell 38, 576-589. doi: 10.1016/j.molcel.2010.05.004

Hillerich, B., and Westpheling, J. (2006). A new GntR family transcriptional regulator in Streptomyces coelicolor is required for morphogenesis and antibiotic production and controls transcription of an $\mathrm{ABC}$ transporter in response to carbon source. J. Bacteriol. 188, 7477-7487. doi: 10.1128/jb.008 98-06

Hoskisson, P. A., and Rigali, S. (2009). Chapter 1: variation in form and function the helix-turn-helix regulators of the GntR superfamily. Adv. Appl. Microbiol. 69, 1-22. doi: 10.1016/S0065-2164(09)69001-8

Kabsch, W. (2010). XDS. Acta Cryst. 66, 125-132.

Lamzin, V. S., Perrakis, A., and Wilson, K. S. (2012). “ARP/wARP - automated model building and refinement international tables for crystallography," in Crystallography of Biological Macromolecules, 2nd Edn, eds E. Arnold, D. M. Himmel, and M. G. Rossmann (New York, NY: Kluwer Academic Publishers).

Langmead, B., and Salzberg, S. L. (2012). Fast gapped-read alignment with bowtie 2. Nat. Methods 9, 357-359. doi: 10.1038/nmeth.1923

Lejon, S., Cramer, J. F., and Nordberg, P. (2008). Structural basis for the binding of naproxen to human serum albumin in the presence of fatty acids and the GA module. Acta Crystallogr. Sect. F Struct. Biol. Cryst. Commun. 64, 64-69. doi: 10.1107/S174430910706770X

Li, B., and Dewey, C. N. (2011). RSEM: accurate transcript quantification from RNA-Seq data with or without a reference genome. BMC Bioinformatics 12:323. doi: 10.1186/1471-2105-12-323 
Liu, H., Wang, K., Lindås, A.-C., and Peeters, E. (2016). The genome-scale DNA-binding profile of BarR, a $\beta$-alanine responsive transcription factor in the archaeon Sulfolobus acidocaldarius. BMC Genomics 17:569. doi: 10.1186/ s12864-016-2890-0

Marabotti, A., Spyrakis, F., Facciano, A., Cozzini, P., Alberti, S., Kellogg, G. E., et al. (2008). Energy-based prediction of amino acid-nucleotide base recognition. J. Comput. Chem. 29, 1955-1969. doi: 10.1002/jcc.20954

Martin, M. (2011). Cutadapt removes adapter sequences from high-throughput sequencing reads. EMBnet.J. 17, 10-12.

Maxam, A. M., and Gilbert, W. (1980). Sequencing end-labeled DNA with basespecific chemical cleavages. Meth. Enzymol. 65, 499-560. doi: 10.1016/s00766879(80)65059-9

Murshudov, G. N., Skubak, P., Lebedev, A. A., Pannu, N. S., Steiner, R. A., Nicholls, R. A., et al. (2011). REFMAC5 for the refinement of macromolecular crystal structures. Acta Crystallogr. D Biol. Crystallogr. 67, 355-367. doi: 10.1107/ S0907444911001314

Nguyen, N. T. T., Contreras-Moreira, B., Castro-Mondragon, J. A., Santana-Garcia, W., Ossio, R., Robles-Espinoza, C. D., et al. (2018). RSAT 2018: regulatory sequence analysis tools 20th anniversary. Nucleic Acids Res. 46, W209-W214. doi: $10.1093 /$ nar/gky317

Nguyen-Duc, T., Peeters, E., Muyldermans, S., Charlier, D., and Hassanzadeh-Ghassabeh, G. (2013a). Nanobody(R)-based chromatin immunoprecipitation/micro-array analysis for genome-wide identification of transcription factor DNA binding sites. Nucleic Acids Res. 41:e59. doi: 10.1093/nar/gks1342

Nguyen-Duc, T., van Oeffelen, L., Song, N., Hassanzadeh-Ghassabeh, G., Muyldermans, S., Charlier, D., et al. (2013b). The genome-wide binding profile of the Sulfolobus solfataricus transcription factor Ss-LrpB shows binding events beyond direct transcription regulation. BMC Genomics 14:828. doi: 10.1186/ 1471-2164-14-828

Oberto, J. (2013). SyntTax: a web server linking synteny to prokaryotic taxonomy. BMC Bioinformatics 14:4. doi: 10.1186/1471-2105-14-4

Ostash, B., Rebets, Y., Myronovskyy, M., Tsypik, O., Ostash, I., Kulachkovskyy, O., et al. (2011). Identification and characterization of the Streptomyces globisporus 1912 regulatory gene lndYR that affects sporulation and antibiotic production. Microbiology 157, 1240-1249. doi: 10.1099/mic.0.045088-0

Peeters, E., Peixeiro, N., and Sezonov, G. (2013). Cis-regulatory logic in archaeal transcription. Biochem. Soc. Trans. 41, 326-331. doi: 10.1042/BST20120312

Peeters, E., Thia-Toong, T.-L., Gigot, D., Maes, D., and Charlier, D. (2004). Ss-LrpB, a novel Lrp-like regulator of Sulfolobus solfataricus P2, binds cooperatively to three conserved targets in its own control region. Mol. Microbiol. 54, 321-336. doi: 10.1111/j.1365-2958.2004.04274.x

Peeters, E., Wartel, C., Maes, D., and Charlier, D. (2007). Analysis of the DNAbinding sequence specificity of the archaeal transcriptional regulator Ss-LrpB from Sulfolobus solfataricus by systematic mutagenesis and high resolution contact probing. Nucleic Acids Res. 35, 623-633. doi: 10.1093/nar/gkl1095

Pérez-Rueda, E., Hernandez-Guerrero, R., Martínez-Núñez, M. A., ArmentaMedina, D., Sanchez, I., and Ibarra, J. A. (2018). Abundance, diversity and domain architecture variability in prokaryotic DNA-binding transcription factors. PLoS One 13:e0195332. doi: 10.1371/journal.pone.0195332

Pérez-Rueda, E., and Janga, S. C. (2010). Identification and genomic analysis of transcription factors in archaeal genomes exemplifies their functional architecture and evolutionary origin. Mol. Biol. Evol. 27, 1449-1459. doi: 10. 1093/molbev/msq033

Pfaffl, M. W. (2001). A new mathematical model for relative quantification in real-time RT-PCR. Nucleic Acids Res. 29:e45.

Rigali, S., Derouaux, A., Giannotta, F., and Dusart, J. (2002). Subdivision of the helix-turn-helix GntR family of bacterial regulators in the FadR, HutC, MocR, and YtrA subfamilies. J. Biol. Chem. 277, 12507-12515. doi: 10.1074/jbc. m110968200

Robinson, J. T., Thorvaldsdóttir, H., Wenger, A. M., Zehir, A., and Mesirov, J. P. (2017). Variant review with the integrative genomics viewer. Cancer Res. 77, e31-e34. doi: 10.1158/0008-5472.CAN-17-0337

Robinson, M. D., McCarthy, D. J., and Smyth, G. K. (2010). edgeR: a Bioconductor package for differential expression analysis of digital gene expression data. Bioinformatics 26, 139-140. doi: 10.1093/bioinformatics/btp616

Rozen, S., and Skaletsky, H. (2000). Primer3 on the WWW for general users and for biologist programmers. Methods Mol. Biol. 132, 365-386. doi: 10.1385/159259-192-2:365

Salzberg, L. I., Luo, Y., Hachmann, A.-B., Mascher, T., and Helmann, J. D. (2011). The Bacillus subtilis GntR family repressor YtrA responds to cell wall antibiotics. J. Bacteriol. 193, 5793-5801. doi: 10.1128/JB.05862-11

Smollett, K. L., Smith, K. M., Kahramanoglou, C., Arnvig, K. B., Buxton, R. S., and Davis, E. O. (2012). Global analysis of the regulon of the transcriptional repressor LexA, a key component of SOS response in Mycobacterium tuberculosis. J. Biol. Chem. 287, 22004-22014. doi: 10.1074/jbc.M112.357715

Suvorova, I. A., Korostelev, Y. D., and Gelfand, M. S. (2015). GntR family of bacterial transcription factors and their DNA binding motifs: structure, positioning and co-evolution. PLoS One 10:e0132618. doi: 10.1371/journal. pone. 0132618

Suzuki, S., and Kurosawa, N. (2016). Disruption of the gene encoding restriction endonuclease SuaI and development of a host-vector system for the thermoacidophilic archaeon Sulfolobus acidocaldarius. Extremophiles 20, 139-148. doi: 10.1007/s00792-016-0807-0

Tsypik, O., Yushchuk, O., Zaburannyi, N., Flärdh, K., Walker, S., Fedorenko, V., et al. (2016). Transcriptional regulators of GntR family in Streptomyces coelicolor A3(2): analysis in silico and in vivo of YtrA subfamily. Folia Microbiol. 61, 209-220. doi: 10.1007/s12223-015-0426-7

Vindal, V., Suma, K., and Ranjan, A. (2007). GntR family of regulators in Mycobacterium smegmatis: a sequence and structure based characterization. BMC Genomics 8:289. doi: 10.1186/1471-2164-8-289

Wagner, M., van Wolferen, M., Wagner, A., Lassak, K., Meyer, B. H., Reimann, J., et al. (2012). Versatile genetic tool box for the crenarchaeote Sulfolobus acidocaldarius. Front. Microbiol. 3:214. doi: 10.3389/fmicb.2012.00214

Yoshida, K. I., Fujita, Y., and Ehrlich, S. D. (2000). An operon for a putative ATPbinding cassette transport system involved in acetoin utilization of Bacillus subtilis. J. Bacteriol. 182, 5454-5461. doi: 10.1128/jb.182.19.5454-5461.2000

Zhang, Y., Werling, U., and Edelmann, W. (2012). SLiCE: a novel bacterial cell extract-based DNA cloning method. Nucleic Acids Res. 40:e55. doi: 10.1093/nar/ gkr1288

Zhou, X., Yan, Q., and Wang, N. (2017). Deciphering the regulon of a GntR family regulator via transcriptome and ChIP-exo analyses and its contribution to virulence in xanthomonas citri. Mol. Plant Pathol. 18:24. doi: 10.1111/mpp. 12397

Conflict of Interest Statement: The authors declare that the research was conducted in the absence of any commercial or financial relationships that could be construed as a potential conflict of interest.

Copyright (c) 2019 Lemmens, Tilleman, De Koning, Valegård, Lindås, Van Nieuwerburgh, Maes and Peeters. This is an open-access article distributed under the terms of the Creative Commons Attribution License (CC BY). The use, distribution or reproduction in other forums is permitted, provided the original author(s) and the copyright owner(s) are credited and that the original publication in this journal is cited, in accordance with accepted academic practice. No use, distribution or reproduction is permitted which does not comply with these terms. 